\title{
Sex versus Gender: Are we there yet? A biological location for gender, not sex.
}

Bobbi M. Woodhill

University of New England, Armidale, Australia;

Dr. Curtis A. Samuels

University of California, Berkeley.

\section{INTRODUCTION}

It has recently been proposed that "male and female brains are monomorphic, not dimorphic, in structure and function" (Eliot, Ahmed, Khan, \& Patel, 2021, p. 2), and we agree discussing human sex differences and behavior "remains an exciting yet challenging task that should [still] occupy researchers for decades to come" (Zell, Krizan, \& Teeter, 2015, p. 18). The debates are certainly not yet over (Fine, 2020).

A recent a masterful reductionist debate on sex/gender differences, or rather the absence of the same, makes a valid conclusion that the hundreds of studies reviewed fall prey to being underpowered and or unreplicated. The authors conclude the human brain is not sexually dimorphic either structurally (accounting for overall size) or functionally. Yet there is also a paradox in with the statement that differences are insignificant "except for a few behaviors" (Eliot et al. (2021, p. 6), for example in aggression. The very fact that differences in aggression levels are widely agreed upon ipso facto refutes the claim there are no gender differences in behavior. Of these' few behaviors', it is unknown precisely "what advantage the dimorphism [if any] gives males and females in terms of function" (McCarthy et al., 2017, p. 24).

Aggressive and anti-social behavior is linked to prioritized genes highly expressed in the amygdala and putamen, as well as in the cerebellum and frontal cortex (López et al., 2020). Sex differences in copulatory and post-copulatory behavior might be considered adaptations that serve particular evolutionarily and social needs, so long as the adaptions do not favor the evolution of groups over individual evolution and vice versa (Parker, 2021).

Our review will suggest the well-established small to moderate gender differences in a 'few behaviors' are clearly relatable to dimorphic reproductive demands instead of the general behavioural cognitive mosaic. To do this we focus and explore the 'several key areas', and the 'few behaviors' accepted as sexually dimensional (Hyde et al., 2018; Zell et al., 2015; Carothers \& Reiss, 2013; Hyde, 2005). Our review finds support for the hypothesis that 
innate-based difference enables competencies that match reproductive roles, demands, specializations, responsiveness, and cognitions; and specifically empathy and aggression. We will present a case for innate gender (a biological location) in both the physical and cognitive behaviors relevant to reproduction centered in interconnected neural networks within the reproductive axis (RA).

The past decades have seen the pendulum of sex differences swing through alternative affirmation and denial (Kret \& De Gelder, 2012). Nonetheless, of the many sex differences found in the central nervous system, around ten can be linked to sex differences in behavior (Zell et al., 2015). Dimorphism forms the somatic and neural foundations for sexdifferentiated skills or preferences (Grabowska, 2017) and most notably in aggression levels (see Zell et al., 2015) and empathy (see this paper). Interestingly, however, and perhaps hinting at an answer, several cognitive behaviors relevant to reproduction are differentially associated with the limbic system (Hoffman, 2013; Bonelli \& Cummings, 2007) as part of an integrated network of intrinsic links that unite sex, emotion, to facilitate species survival (Yao, Bergan, Lanjuin, \& Dulac, 2017).

\section{Old problems}

The problems with 'difference' research have been well documented. Confounding results have been attributed to inconsistent definitions and methodology; categories vs. dimensions, fixed vs. flexible difference, false positives, small sample size, small effect size, absence of studies reporting null findings, and animal comparisons to humans (Fine, 2020; Hyde, 2005).

Concerning effect size, a significant amount of research supports the 'similarities hypothesis' (Hyde, 2005, 2014), which states that differences in most, but not all, psychological variables are small (Joel, 2011; Hines, 2011). Furthermore, a significant amount of research supports the 'similarities hypothesis' (Hyde, 2005, 2014). Of critical relevance to this current article are the phrases 'except for a few' and 'not all. These seemingly innocuous throw-away phrases became the cornerstone of this review.

Concerning animal studies and despite the moral indignation felt by some with animal comparisons (van der Dennen, 2005), differences in human and animal brains have shown similar comparative morphology (Guillamon, Junque, \& Gómez-Gil, 2016). Humans share an evolutionary history, as do other mammals that are good for illustrating biological principles if nothing else (van der Dennen, 2005). The spinal nucleus of the bulbocavernosus (SNB) of the lumbar spine in rodents provides an example of a sexually differentiated structure in which testosterone plays a pivotal role. The castration of neonatal male rodents causes the SNB system to die (Zuloaga et al., 2009).

In rodents the perinatal neuro-estrogens of testicular origin act to organize the sexually dimorphic structures of the preoptic area (POA) and the bed nucleus of the stria terminalis (BNST) (Tsukahara, S., \& Morishita, M. (2020). In rodents, the sexually dimorphic nucleus of the preoptic area (SDN-POA) shows a high degree of sexual dimorphism, males $>$ females by several-fold (Negri-Cesi et al., 2004). Animal studies can show neural and endocrine systems that likely account for the development and sensitivity of gendered 
parental behavior across the lifespan (Champagne \& Curley, 2016; Lonstein, Pereira, Marler, \& Morrell, 2014). Nevertheless, gender is a concept relevant solely to humans.

At the same time, this paper does not deny psycho-social influences on postnatal gender. It locates an uninfluenced (life-naive) prenatal gender as biological and located initially in a physiological place unrelated to later psycho-social influences. With this in mind, and due to ethical restraints in human studies, the reductionist study of animals can be legitimate in searching for understanding in the endocrinology and neurobiology of, specifically, for example, nurturant behaviors that are universal across many species and may underpin human behavior (Lonstein et al., 2014).

\section{AIM}

This review began with questions. Considering most species consist of two sexes and only female mammals fall pregnant and lactate, it seems logical to ask why there are not innate cognitive differences relative to the physical differences in the reproductive processes? If so, could we label this difference 'gender,' and could a part or parts of the brain comprise this 'gender'?

The realization that the similarities hypothesis of a sex/gender mosaic (see later) does not account for all human behavior brought focus to this review allowed us to;

(1) split the behavioral domain of the general cognitive mosaic of functions such as reasoning, organization, and execution of complex thoughts, from those cognitions, explicitly related to reproduction;

(2) examine the possible location of biological origins for those cognitions associated with reproduction to examine whether they are dimorphic;

(3) present the case that dimorphic neural regions and their associated behaviors are the sources of gender;

(4) examine the same regions in the trans['] (Tx) community for dimorphisms. The outcomes may support or otherwise the biological source of gender in both the cisgender and Tx communities.

We are not discussing why did sex evolve or why there are only two sexes (Parker (2021), however, it is noteworthy that we are a sexually reproducing species where sexual behavior [physical and cognitive] is a subset of reproduction (van der Dennen, 2005). "Sex differences in behavior are ubiquitous among sexually reproducing species and presumably contribute in some way to the reproductive success of the organism" (McCarthy et al., 2017, p. 5). For the good of their kind, sexually reproducing species are best suited to incorporate beneficial genetic mutations, exclude deleterious mutations, and keep up with environmental change (van der Dennen, 2005).

\footnotetext{
${ }^{1}$ This community considers any other term other than 'trans' as discriminatory.
} 
Our review will focus on the asymmetry of behavior from a somewhat evolutionary perspective.

An evolutionary view of sex differences in behavior is not a relapse into the obsolete and acrimonious nature-versus-nurture debate. Instead, it provides a general framework to understand them as consequences of different reproductive and parental investment strategies.

(van der Dennen, 2005).

We will suggest the sense of a gendered self has evolved over millions of years of different selection processes and is related to cognitive dimorphic behaviors under the heterogeneous influence of neural networks in the reproductive axis. 


\section{Selected definitions / abbreviations}

Cisgender - denoting a person whose sense of identity corresponds with their sex assigned at birth.

CNS - central nervous system.

$D T I$ - diffusion tensor imaging.

$f M R I$ - functional magnetic resonance imaging.

$M R I$ - magnetic resonance imaging.

$F t M$ - female to male (female sex assigned at birth).

$M t F$ - male to female (male sex assigned at birth).

$R A$ - reproductive axis

$G n R H$ - gonadotropin-releasing hormone.

$L H$ - luteinizing hormone.

FSH - follicle-stimulating hormone.

$G M$ - gray matter.
PFC - prefrontal cortex.

$W M-$ white matter.

$s M R I$ - structural magnetic resonance imaging.

$H P G$ - hypothalamic-pituitary-gonadal axis.

$H P A$ - hypothalamus-pituitary-adrenal axis.

MPOA - medial preoptic area of the hypothalamus.

$P O A$ - preoptic area, a region of the hypothalamus.

INAH3 - third interstitial nucleus of the anterior thalamus.

$B N S T$ - the bed nucleus of the stria terminalis.

$T$ - testosterone.

$T B V$ - total brain volume

Tx - trans 


\section{Centuries-old categories}

Leaving socio-politics aside, for now, two sexes and two genders have been unproblematic in the fabric of everyday life, at least for those who conform. However, the notion of 'a gendered self' only seems explicable philosophically. Indeed, it is generally agreed our sense of maleness or femaleness resides in the brain (Legato, 2018). The anatomical location for gender has been considered the brain (Bao \& Swaab, 2011); nonetheless, "the factors that create the gendered brain and gender identity are not yet clearly defined" (Legato, 2018, p. 65).

\section{Terminology}

In discussing sex and gender, language matters (Joel \& Fausto-Sterling, 2016). The terms' sex' and 'gender' remain actively entangled with each other, and neuroscience has not provided a reasoned account for where sex ends and gender begins (Kaiser, 2012), while psychology has recently presented them as the blended notion of sex/gender. Avoiding the conflation of the categories of sex and gender (Francis, 2012) has inspired some 21"-century thinking, yet from scientific to lay communities, definitions of 'sex' and 'gender' remain confusing and divisive.

\subsection{Sex}

We are a sexually reproducing species, and much like the necessity to attain a patient's sex on admission to a hospital emergency department, this article will keep 'sex' as initially defined by Unger (1979) - the body's obvious physical and reproductive anatomy only.

\subsection{Gender}

This article maintains the separation of bodily sex separate from brain sex (gender). Gender is biological and defined as cognitive is not used as a term for social expectations or social roles.

We present a framework for biological gender as the subconscious neurological consequence of the reproductive axis (RA). These networks control both the physical and cognitive behaviors specifically relevant to reproduction.

\subsection{Dimorphic}

The term 'dimorphic,' meaning occurring in two distinct forms, is used in this article to describe significant differences with some overlap (McCarthy \& Konkle, 2005).

\subsection{Canalized}

Most species maintain abundant genetic variation and experience a range of environmental conditions, yet phenotypic variation is low. That is, development is 
robust to changes in genotype and environment. It has been claimed that this robustness, termed canalization, evolves because of long-term natural selection for optimal phenotypes.

(Siegal \& Bergman, 2002, p. 10528).

In this review, canalized psycho-neuroanatomy refers to that which is moderately focused on male and female endpoints depicting sex differences, i.e., psycho-neuroanatomy is canalized, or "weakly bimodal" (Joel \& McCarthy, 2017, p. 381).

\section{SEX / GENDER AS MOSAIC}

This paper focuses on universal sex differences in behavior - those unrelated to outside influences and away from many behaviors widely accepted as a mosaic amongst the sexes.

Questions about sex differences remain; from what, and from where precisely could a gendered self-originate?

"How is it the genetic and hormonal components of bodily sex create two distinctly different reproductive systems - and yet human male and female behavior shows itself to be flexible and surprisingly similar?"

(Fine, p. 1, 2020)

Considering we do not have heteromorphic sex chromosomes, and only females endure the processes of ovulation, pregnancy, and lactation, and males do not, we can reasonably ask why wouldn't there be differences in innate cognitions relative to the differences in the reproduction burden? Such astounding physical differences firmly suggest the probability of cognitive differences, and we can ask this question another way:

"...it would be highly negligent of evolution (or Nature, or God) to create a sexually dimorphic species without at the same time 'programming' or 'wiring,' or otherwise preparing the individuals for the divergent strategies, functions, and roles they have to play during their lifetimes, especially in the reproductive domain..."

(van der Dennen, 2005, p., 2).

Furthermore, there is comprehensive agreement many neurological disorders affect males and females divergently. For example, in autism spectrum disorder, attention deficit hyperactivity disorder, alcohol abuse, dyslexia, anxiety disorders, depression, and eating disorders (reviewed in Eliot et al., 2021). Moreover, Parkinson's disease, congenital adrenal hyperplasia, Ra-R2 deficiency, complete androgen insensitivity syndrome, aromatase deficiency (see Negri-Cesi et al., 2004). These disparities suggest essential sex/gender differences in brain structure or function (see Eliot et al., 2021).

"Though males are more frequently afflicted with neurodevelopmental disorders, when such conditions arise in the female, a more severe form is usually manifest" (Eme, 1992, p. 384). 
For example, mental retardation dominates in boys, but its morbidity is more significant in girls.

Similarly, autism is more common in boys, but girls with autism suffer a lower IQ. The preponderance of conduct disorder in boys is decisive. Delinquent girls are usually exposed to worse developmental environments than boys. Ratios of boys to girls with ADHD have been reported as disparate as 9:1 (Eme, 1992).

Confining sex/gender differences to psychiatric and neurological conditions alone would be negligent of science. To borrow from Eliot et al. (2021), disparate occurrences of childhood disorders necessitate differences in the brain.

Recent theories have argued there is no natural dichotomy of gendered behavior and propose the notional merging of otherwise distinct categories for sex and gender into a mosaic of sex/gender (Joel \& McCarthy, 2017; Rippon, Jordan-Young, Kaiser, \& Fine, 2014). Their arguments favor we desist labelling sex and gender as separate variables and combine them into the singular term - 'sex/gender' (Fine, Joel, \& Rippon, 2019; Kaiser, 2012), or 'gender/sex' (van Anders, 2015).

Theoretically, the notion of human behavioral overlap or mosaic removes the need to separate sex and gender. However, the idea that prenatal brains are intersex and belong to a single heterogeneous population is an enormous ambition, according to Pavlova (2017). Is this debate now over, or do we continue to argue the case for gender as biologically distinct from body sex, dimorphic, yet more focused towards male and female endpoints of a spectrum, i.e., canalized? These questions raise a conundrum. In a tiny percentage of people, $0.5-1.4 \%$ of natal males and $0.2-0.3 \%$ of natal females (Theisen et al., 2019), this alignment is unconventional.

There is a paucity of replicated studies comparing cis- and trans (Tx) subjects, with just one of total brain volume showing it is typical of birth-assigned sex. Furthermore, findings on other measures of gender in the brain are disparate and conflicting (Fine, Joel, \& Rippon, 2019). The authors conclude this reinforces the view "brain volume, gray matter (GM), and white matter (WM) are merely scaled to the rest of anticipated body morphology and unrelated to gender identity or behavior," leading to "the more parsimonious conclusion...that distinct markers of male and female identity do not exist." Furthermore, Eliot et al. (2021) challenge the idea of a spectra of brain gender and add male and female psychological profiles are multidimensional mosaics of behavior. How can this be?

A sex/gender mosaic appears to bypass a biology of Tx children who identify as gendered opposite to their natal sex as early as age two (Zucker, Bradley, \& Sanikhani, 1997), or age three (Olson \& Gülgöz, 2018; Hewitt et al., 2012) and irrespective of what their body structures are scaled to fit in the future. It also disregards children who persist post-puberty, whose reproductive behavior is not always conventional, and late-onset dysphoric individuals who identify with a gender opposite to their birth sex. Our hypothesis speaks directly to early-onset trans (Tx) individuals who have not had sufficient time to absorb and learn the nuances or politics of sex and gender so often assumed the sole source of gender, loosely defined. 
The presence of genes (X or $\mathrm{Y}$ ) precedes gonad development. Gonads secrete sex steroid hormones. The sex-determining region $\mathrm{Y}(S R Y)$ on the $\mathrm{Y}$ chromosome determines the development of testes in males. Around the time of birth, the sex steroid hormones exert permanent changes in the CNS (Hines, 2020; Zuloaga et al., 2009).

In the absence of an $S R Y$ gene on a Y chromosome, the embryo's bipotential primordial genital structures develop into female internal and external reproductive organs (Tasopoulos, 2018). This development accounts for body morphology but does not account for post-natal gender incongruence. The dominance of testosterone from around birth results in the fetus's masculinization (Zuloaga et al., 2009; Wizemann \& Pardue, 2001). No matter which is considered the default state for human embryos, male or female (Joel, Garcia-Falgueras, \& Swaab, 2020), gonad formation precedes neural tube development. The brain's high function areas have been labelled initially intersex and not dimorphic (Hyde et al., 2018).

Supporting the similarities hypotheses and in terms of statistical effect size, many differences are small $(\mathrm{d}=0.20)$ to moderate $(\mathrm{d}=0.50)$ (Hyde, 2005, 2014), with distributions on most variables overlapping by around $85 \%$ (Zell et al., 2015; Cohen, 1988).

Nevertheless;

Even if other factors such as culture and environment influence gender identity development, evidence from individuals with intersex conditions suggests the critical role of prenatal androgen exposure in sex differentiation of the brain.

(Ristori et al., 2020, p. 4).

For example, post orchidectomy, brain masculinization may occur in $46 \mathrm{XY}$ individuals with cloacal exstrophy assigned to female at birth (Ristori et al,,2020). Thus, gender identity in the intersex and Tx communities as separate from bodily sex makes the notion of a single category of sex/gender awkward, as they do for the totality of cultural and social origins of gender. The presentation of differential cognitive behaviors relevant to reproduction, separate to physical reproductive and high function areas of mosaic behavior, will make the sex/gender notion challenging to maintain for all behaviors.

Professional and non-professional articles continue to present gender as a person's sense-ofself within several intersecting factors and influences (Fiani, 2018; Strauss et al., 2017); however, no one has ventured to suggest what the 'factors' that make gender are, nor from where they might originate.

\section{SIGNIFICANT STABLE SEX DIFFERENCES}

Though the 'characteristics' of 'sex-related behavior' relative to the physicality of reproduction are related to the presence of ova or testes and accepted as dimorphic, other sex-related cognitive behaviors have not been explicitly identified. Some see gender as 'subconscious sex' and an intrinsic part of an individual that hardwires traits of one sex or the other into the brain (Serano, 2016). But again, these 'traits' are not deduced. While there appears to be "...much more overlap in the behavioral phenotypes of males and females especially outside the context of reproduction" (McCarthy et al., 2017, p. 24), apart 
from physical behaviors related to mating, clarification of these 'behaviors' and 'traits' is missing in the literature.

\subsection{Sex-related behaviors}

Although still contested, small to moderate gender differences are well established in more than a few areas. Differences in toy preferences, levels of empathy $(\mathrm{F}>\mathrm{M})$, aggression $(\mathrm{M}>\mathrm{F})$, mental rotation $(\mathrm{M}>\mathrm{F})$, and social dominance $(\mathrm{M}>\mathrm{F})$ are considered large $(d>0.8)$ (Hines, 2020). At least ten sex differences (discussed later) are reported as moderate to large $(\mathrm{d}=0.50-0.80)$ (Zell et al., 2015). While witnessing another's pain seems to activate brain regions equally in men and women (Lamm, Decety, \& Singer, 2011), pain tolerance seems to be differential, at least anecdotally, though "genetic effects have been unable to fully explain the variation in pain sensitivity" (Castillo-Fernandez, Spector, \& Bell, 2014, p. 12). Furthermore, considering differences are also likely context-dependent across domains (Del Giudice, Booth, \& Irwing, 2012), small gender differences should not be regarded as trivial (Zell et al., 2015). Furthermore, a 'small' effect size does not equal a trivial effect (Sanchis-Segura et al., 2019).

In their robust article, Eliot et al. agree with "the possibility that there are reliable male/female differences in certain populations under very specific conditions (Eliot et al., 2021, p 66).

Additionally;

Even behaviors such as depressive symptoms with statistically modest effect sizes (e.g., $d$. .36) can result in a multifold risk of suffering from clinically profound distress in one sex, e.g., in females.

(Vigil, 2009, p. 381).

How the human brain is organized into interconnected compartments or regions is revealed in neurological imaging. The Human Brainnetome Atlas has subdivided the entire human brain into 210 cortical and 36 subcortical subregions (Fan et al., 2016). The majority of regions are similarly sized in males and females once corrected for total brain volume (TBV) (Eliot et al., 2021), leaving some regions dimorphic between the sexes. Research into the outcomes of differing brain size of itself is conflicting. Insects with tiny brains, for example, honeybees (Chittka \& Niven, 2009) and enormous brains, for example, elephants (Nave et al., 2019), are capable of complex cognition and social skills. However, in humans, Nave et al. (2019) report greater TBV is associated with greater intelligence across sex and age, with individual differences explained by gray matter volume. Indeed, intelligence levels do not appear sexually dimorphic but are mosaic (Halpern \& Wai, 2020; Joel \& McCarthy, 2017; Jones \& Lopez, 2014).

Nevertheless,

While acknowledging there are reliable sex-related differences in the organization of the neurological substrates underlying [for example] decision making and emotion, it has 
been challenging to speculate on biological, evolutionary, or psychosocial reasons driving these differences.

(Reber \& Tranel, 2017, p. 275).

These authors offered that different parental biological and social roles in childbirth and childrearing may play a role (Reber \& Tranel, 2017).

The bio-psycho-social model and psychological constructionism model of identity development combine the experience and learning of sensations from inside and outside the body. Proposed sex differences in the brain (structural and functional) have historically been attributed to the combined effects of hormones, genes, epigenetics, and the social environment (Feldman \& Lindquist, 2021; Ratnu, Emami, \& Bredy, 2017; Eagly \& Wood, 2013). Research into gender identity still favors this thought line (Auger, \& McCarthy, 2017; McCarthy, Pickett, Van Ryzin, \& Knight, 2015). Nonetheless, biology and culture work hand in hand, and it appears difficult to impossible to separate the influences of one from the other (Joel et al., 2020; Fine et. al, 2019). Further, "gender incongruence is a complex multifactorial trait, involving intricate interactions among steroids, steroids receptors, and multiple genes and polymorphisms" (Fernandez et al., 2020, p. 498).

On the other hand, what do universal, stable, significant gender differences mean? This article has not abandoned dimorphic signalling differences and presents sex, gender, and signalling most relevant to reproduction, as significantly female-typical or male-typical (O’Hanlan, Gordon, \& Sullivan, 2018; Sisk, 2016; Mustanski et al., 2005). This dimorphism should not be unsurprising in a sexually reproducing mammalian species.

Universal early sex differences in cognitive signalling, unrelated to outside influences and removed from the behaviors accepted as a mosaic, could arguably be those relevant to reproduction and survival. Following research into the differences in neural and endocrine development, differences in the reproductive burden on ciswomen compared to cismen, and research into the Tx community, this article presents a case for the physical location of an internal and perceptual sense or feeling of gender associated with the RA and the cognitive behaviors differentially linked with reproduction throughout the lifespan.

To associate gender with the RA, the RA must be dimorphic and canalized towards female and male endpoints of a spectrum, as are, for example, sexual orientation (Savin-Williams, 2016) and intersex conditions (García-Acero et al., 2020). If specific brain regions are essential to specific cognitions, and these regions are dimorphic, it follows that the associated behaviors are likely dimorphic. This process, termed 'equifinality' by its creator, is defined as a common outcome derived from different pathways. So although gender is a complex multifactorial trait where outcomes may not be linearly determined, as we shall see, a common outcome can derive from different pathways. For example, a normal organism's development from a whole, divided, or two fused ova (Von Bertalanffy, 1993). 


\subsection{Reproductive Axis}

The reproduction axis stems from the testes, ovaries, and on to the limbic system. The main components of the limbic system are the hippocampus, the amygdala, and the hypothalamus (Roxo et al., 2011). Traditionally the RA consists of five main components: the extrahypothalamic central nervous system (CNS), pituitary, testis, ovaries (Acevedo-Rodriguez et al., 2018; Pejić et al., 2015; Klein, Wan, Kamyab, Okuda, \& Sokol, 1994), which are all target organs of sex steroid hormones (Ruiz-Cortes, 2012; Wierman, 2007). Under a broad umbrella, the RA can be considered as consisting of any organ in the interconnected network of neurons targeted by sex steroids.

The RA is a tightly regulated feedback loop paramount to reproductive potential (AcevedoRodriguez et al., 2018; Couse et al., 2003; Klein et al., 1994). Control of the RA occurs at all levels. It is crucial for female reproduction, where neuroendocrine control lays with gonadotropin-releasing hormone $(\mathrm{GnRH})$ neurons dispersed from the hypothalamic region of the limbic system (Alzahrani et al., 2019; Acevedo-Rodriguez et al., 2018). Increases in $\mathrm{GnRH}$ are required for a luteinizing hormone (LH) surge and, consequently, ovulation (Acevedo-Rodriguez et al., 2018). The RA further coordinates the production and secretion of the gonadotropins, including luteinizing hormone (LH) and follicle-stimulating hormone (FSH) from the anterior pituitary, which in turn stimulates the release of the sex steroids, androgens, estrogens, and progesterone produced primarily by the ovary, corpus luteum, and adrenals (Blair et al., 2015).

Regulation of reproductive circuitry in the brain includes kisspeptin neurons. AcevedoRodriguez et al. (2018) report kisspeptin detection primarily in two regions of the hypothalamus and preoptic area. It is an important hormone that starts the release of several other hormones. Kiss 1 gene expression is more generous in females than males who do not show a LH surge (Acevedo-Rodriguez et al., 2018). Estrogen and androgen receptors show high distribution levels in the pituitary, hypothalamus, amygdala, putamen, ovaries, testes, and uterus (Denley, Gatford, Sellers, \& Srivastava, 2018; Swaab, 2004; Sato et al., 2004; McEwen, 2001); in other words, in the reproductive axis overall.

In line with locating biological gender in uninfluenced (life-naive) in utero, one such study (gestational age 25-39 weeks), reported differences between male and female fetuses in FC within and between seven neural networks, namely, between cortical and sub-cortical regions and specifically between the prefrontal cortex (PFC), superior frontal gyrus (SFG), and visual cortex. The authors claim this as evidence development of regions of the fetal brain varies by sex which likely acts as precursor to life-long differences in connectivity (Wheelock et al., 2019). The prefrontal cortex is liberally connected with many parts of the brain, notably cortical regions and limbic and midbrain structures involved in affect, memory, and reward (Fuster, 2009). 
The putamen, thalamus, hippocampus, hypothalamus, and amygdala are repeatedly shown to be dimorphic in post-mortem and in-vivo imaging studies (Lotze et al., 2019; Goldstein et al., 2001). Though these studies are not replicated elsewhere, the two subcortical regions that differ across various studies are the putamen and amygdala (Eliot et al., 2021). To investigate whether there are distinct neuroanatomical signatures of cisgender and Tx male and cisgender and Tx female gender identity, a sMRI study of gray matter (GM) tissue maps demonstrated "the neuroanatomical sex classifier trained on the cisgender participants (FC vs. MC) correctly separated biological women from men" (Baldinger-Melich et al., 2019, p. 1348). However, the authors could not detect distinct neuroanatomy for gender incongruence (Baldinger-Melich et al., 2019).

This current paper considers the cortex and all its subsystems in the limbic region hippocampus, amygdala, and hypothalamus - as parts of the RA. A review of the literature will demonstrate how sections of the RA are dimorphic or canalized towards female and male endpoints.

Studies based on large samples reveal, with moderate significance $(d=0.18)$, somewhat consistent different volumes for two subcortical structures: the amygdala and putamen (Lotze et al., 2019; Ritchie et al., 2018). Although absolute difference in amygdala volume was not statistically significant in another study (Marwha, Halari, \& Eliot, 2017).

Genes involved in externalizing signalling, in general, are highly expressed in several cerebral regions, including the amygdala - responsible for experiencing emotion, and the putamen - responsible for habit formation and motor control (López., Pol, Franke, \& Klein, 2020).

\subsubsection{Amygdala}

The limbic system's amygdala region is a paired or bi-lobal structure located in the medial temporal lobe, just anterior to the hippocampus (Salzman, 2021). As part of the RA, the amygdala region is broader in cismen and with a higher density of androgen than estrogen receptors (see, for example, Halpern, 2013). This difference develops during puberty when amygdala size increases in both sexes (Goddings et al., 2014). As part of the limbic system, the amygdala is the most frequently involved in emotion processing structure (Ling et al., 2020; Kaczkurkin et al., 2005).

Several studies show the amygdala as crucially involved with enhanced memory of emotional arousal and processing (von Polier et al., 2020; Flasbeck, Enzi, \& Brüne, 2019), mediation of reactive and proactive aggression (Kolla et al., 2021; Romero-Martínez et al., 2019; Yang, Joshi, Jahanshad, Thompson, \& Baker, 2017).

\subsubsection{Puteman}

The putamen lies in the subcortical region as a part of the basal ganglia (Ghandili \& Munakomi, 2020). It plays a role in facilitating movement by history-based motivation to act for reward (Muranishi et al., 2011; Mink, 1996), moderation of physical aggression (Kolla et al., 2021; Li et al., 2020). Putamen size decreases in both sexes during puberty and more markedly in males (Goddings et al., 2014). A study of 20 year-olds observed a 
positive association between aggressive signalling and structures in functional networks, including putamen volume (Zhu, Zhou, \& Xia, 2019). Nonetheless, having lived 20 years must be taken as a covariate.

\subsubsection{Hypothalamic-pituitary-gonadal (HPG) axis}

A subsystem of the reproductive axis relevant to reproduction and within the limbic system is the hypothalamic-pituitary-gonadal (reproductive gonadal) (HPG) axis (AcevedoRodriguez et al. 2018).

The HPG axis orchestrates physiological processes required for reproduction (Yang, Comninos, \& Dhillo, 2018). The HPG axis's nature was first proposed in the early 1930s (Meethal \& Atwood, 2005). Reproduction governed by the HPG axis is distinguished here from the hypothalamus-pituitary-adrenal (HPA) axis. The HPA axis is a looped neural network between the hypothalamus, pituitary gland, and adrenal glands that play a regulatory role in the menstrual cycle (Roca et al., 2003) and managing the body's response to stress (Rose, 2010).

Stress activates the HPA axis, which can suppress the reproductive system at multiple levels and, in particular, the HPG axis (Calisi, Austin, Lang, \& MacManes, 2018). Anecdotally, this is the reason why many women athletes face temporary amenorrhoea.

Gonads function differently because of differences in the HPG axis, and there are functional differences in various activity centers in the brain relative to the HPG (Hines, 2020; Acevedo-Rodriguez et al., 2018). Activation of the hypothalamic-pituitary-gonadal (HPG) axis resulting in gonadal maturation signifies the onset of puberty (MacMaster et al., 2007). This activation leads to increases in levels of luteinizing hormone, estradiol (females only), follicle-stimulating hormone (females only), and testosterone (Peper et al., 2010). Although the HPG axis is possibly linked to and modulated by stress hormone signalling from the HPA axis (Luine, 2014), and there are gender differences in response to stress (HinojosaLaborde, Chapa, Lange, \& Haywood, 1999); this discussion is restricted to the HPG axis as it is a well-regulated endocrine system allowing for successful reproduction (AcevedoRodriguez et al., 2018).

Differential hormone exposure may influence structural sex differences in the Human CNS. These differences may involve the corpus callosum, anterior commissure, third interstitial nucleus of the anterior thalamus (INAH3), and BNST (Zuloaga et al., 2009). Both the BSTc and INAH3 are reportedly larger in men (TBV adjusted) than in women (Hines, 2020; Smith, Junger, Derntl, \& Habel, 2015). The presence of HPG hormones, cognate hormones, and their differential receptors strongly suggests their related signalling elicits dimorphic structural and functional instructions during neural development and adult reproductive life (Meethal \& Atwood, 2005; Simerly, 2002).

The HPG axis resets at birth due to the significant decline in estrogen levels following the fetus's disconnection from the placenta (Rogol, 2020). However, disruption of the RA prenatally, specifically the HPG, and during mini-puberty (the 3-6 post-natal months) can lead to anabolic changes in linear growth, genital growth, and tissue growth in sexually 
dimorphic body composition (Rogol, 2020; Kurtoğlu \& Baştuğ, 2014). This disruption implies the RA's significant role in the overall development, and that disruption of the RA could also lead to gender incongruence.

\subsection{Biological / evolutionary purpose of differences}

A recent literature review of 142 metanalyses on brain, sex, and gender identified 22 studies reporting data on dimorphic brain structure and function. According to the authors of this study, there is an increasing body of research suggesting sex differences in several areas of human brain performance exist, i.e., several capacities for performance or behavior and their associated cerebral regions are dimorphic (Pallayova et al., 2019). In the final analysis, performance requiring spatial ability favors males (Zell et al., 2015; Maeda \& Yoon, 2013).

Based on their review, Pallayova et al. (2019) suggest that differences in the amygdala can explain female superiority in long-term memory retrieval (as opposed to visual-spatial memory). Primary cognitive control is sex-specific (Pallayova et al., 2019). Reviewing association studies of $\mathrm{Y}$ chromosome subjects who share alleles from parents sharing common ancestral clans, the authors argued the $\mathrm{Y}$ chromosome might exert a considerable influence on brain function due to inheritance playing out in sex-biased neuropsychiatric disorders (Kopsida, Stergiakouli, Lynn, Wilkinson, \& Davies, 2009).

Anxiety is a cognitive function relative to emotional processing. It reflects processes involved in the negative adaptive regulation of behavior and cognitive control and is significantly greater in women than men. The HPG axis orchestrates physiological processes required for reproduction, and the sex difference in the negative anxiety reflects the influences of gonadal hormones, particularly ovarian hormones (Yang et al., 2018) as well as in fear conditioning (Glover et al., 2012). Neural regions involved as a source of negative anxiety include the anterior cingulate cortex, midcingulate cortex, prefrontal cortex, and supplementary motor areas (Moser, Moran, Kneip, Schroder, \& Larson, 2016).

An fMRI study of arousal rating from neutral to negative imagery, the left hemisphere amygdala, but not the right, demonstrated better memory performance and increasing arousal ratings in women than in men following imagery of function concerning memory for emotional events (Cahill, Uncapher, Kilpatrick, Alkire, \& Turner, 2004).

Though recent meta-analysis of the literature for studies reporting the amygdala volume concluded the amygdala was not sexually dimorphic (Marwha et al., 2017), the functional images in the Cahill et al. (2004) study were spatially normalized, i.e., adjusted for total brain volume (TBV), though that study was underpowered with just 23 participants.

Nonetheless, the studies mentioned above are post-hoc, i.e., subjects studied have already lived a male or female life. On that basis, prior practice or the lack of may be regarded as a covariate. For one example, physical and spatial training can alter cerebral structures (Erickson et al., 2011). Studies involving twins, life-naive and treatment-naive subjects (children) tell another story altogether (see 'Empathy in Childhood' this paper). 


\subsection{Reproductive Behavior}

Recent consistent findings with different samples point to the most significant and most stable gender differences occurring in several areas, both in sickness (Salk, Hyde, \& Abramson, 2017; Loomes, Hull, \& Mandy, 2017; Cohen-Bendahan, Buitelaar, Van Goozen, Orlebeke, \& Cohen-Kettenis, 2005), and in health (Zell et al., 2015; Hyde, 2005).

Examining performance gaps in sport, for example, one can see that the physical gender gap between males and females narrows in rock climbing [an analogue of Neanderthal tree climbing] (Carrol, 2021). Both men and women react physiologically to stress with either a 'fight-or-flight' or a 'tend-and-befriend' response. Both responses have been subject to intense evolutionary pressures (Vogt, 2017; Taylor et al., 2000).

With a focus on evolutionary selection pressures benefiting both self and offspring, there are sex differences in consequent behavior, with men showing more 'fight-or flight' and women showing more 'tend-and-befriend' (Verma, Balhara, \& Gupta 2011).

Fight (aggression) typically characterizes men's behavior under stress, and women's by tend [and befriend] or flight (social withdrawal, substance abuse). This difference may demonstrate how emotional expression for males and females may recruit different cerebral networks (Kret \& De Gelder, 2012).

The ongoing sexual division of labor highlights how males and females may employ their innate abilities to procure resources and achieve cooperation in the care of offspring while also under socialization and culture (Tay, Ting, \& Tan, 2019).

A meta-synthesis of over 20,000 studies provided data from a large subject pool and defeating claims of being underpowered and or unreplicated levelled at many global studies of gender differences. The 'few differences' so often glossed over in other research amount to mental rotation ability, interest in people vs. things, socio-emotional skills, response to noxious stimulation, visually induced fear, peer attachment, confidence in physicality, and aggression (Zell et al., 2015).

In answering what particular evolutionarily / socially purpose these differentials concur, it is not a long bow to draw in suggesting the behavioral arenas of sensorimotor, emotional perception and processing, mathematical and visuospatial abilities, traditionally relate to reproduction. We will explore the two behavioral areas of aggression and empathy to demonstrate behavior especially relevant to reproduction.

\section{SEX-SPECIFIC BEHAVIOR}

Previous studies have reported no differences in the human connectome that could locate gender. Despite this lack of evidence, studies in early-onset Tx individuals show differences in gross and micro brain morphology (Fernandez et al., 20180, including different cerebral connectivity/connectome profiles (Kreukels \& Guillamon, 2016). ${ }^{2}$ The connectome

\footnotetext{
${ }^{2}$ See 'Connectivity / Connectome' later in this article.
} 
incorporates the cerebral network's overall communication architecture, a description of brain connectivity and function rather than anatomical or structural differences.

The dimorphic RA incorporates the brain areas processing cognitions related to reproduction, i.e., within the two dimorphic reproductive systems. In other words, these cognitions are gendered and may be reinforced or not by outside factors such as culture and social learning.

\subsection{Parenting}

Parent and infant gender may vary parent-infant emotional expression. Greater than trivial behavior differences have been presented in the arenas of aggression and sexuality (Hyde et al., 2018), courtship, and care of offspring (Meyer-Bahlburg, 2019). These moderate to large gender differences are notable exceptions to the similarities hypothesis on sex differences with specific bearing.

Hormones are not strictly necessary to express maternal behavior in non-human and human primates. Human females and males of all ages and reproductive conditions can express infant-caregiving behavior (Saltzman \& Maestripieri, 2011). Further, cognitions are the source of the emotional states and individual traits during pre- and postpartum mothering (Lonstein et al., 2014). Nonetheless, the levels of estrogen, progesterone, prolactin, oxytocin, and testosterone $(\mathrm{T})$ present in a parent influence variation in parental behavior both within and between individuals (Saltzman \& Maestripieri, 2011). The different mix of hormones between males and females throughout the lifespan thus becomes relevant to parenting behavior. As Vigil (2009) suggests, "Perhaps the gender-dependent correlates of neural activity reflect neural predispositions in mothers for responses to preverbal infant vocalizations" (p. 402).

\subsection{Is there a Female Brain?}

"Biology has been instrumental in many [of these] narratives, including those that justify gender inequalities based on supposed differences in women's organs, hormones, and brains" (Feldman \& Lindquist, 2021).

The sex-determining region (SRY) on the male's $\mathrm{Y}$ chromosome is responsible for the formation of testes. In the absence of the Y chromosome, ovaries form (Simerly, 2010). This biological sequence has been used to proclaim 'female' is the default sex. If the default state for human embryos is female, then a legitimate question arises: is there a male brain? In order to answer such a question, we ask its equivalent: is there a female brain?

While pre-pubertal levels of the critical steroid hormone progesterone (immunity, sperm production, lactation) are more or less equal (Sippell, Dörr, Bidlingmaier, \& Knorr, 1980), only post-pubertal human females acquire pre- and postpartum neurology. Female hormones are associated with maternal behavior in animals, non-human and human primates (Champagne \& Curley, 2016; Lonstein et al., 2014; Saltzman \& Maestripieri, 2011; Smith et al., 2012). In particular, estrogen receptors emerge within areas of the limbic system's medial preoptic area of the hypothalamus (MPOA) "in mid to late gestation and reach adult- 
like levels at the time of birth" (Champagne \& Curley, 2016, p. 11). The anterior preoptic area (POA) is the region responsible for cycling $\mathrm{GnRH}$ release. At the time of birth, the medial preoptic region (SDN-POA) is sexually dimorphic. Testosterone exposure at around the time of birth causes the SDN-POA volume in males to become "several times greater than in females" (Zuloaga et al., 2009, p. 348).

This cyclical release of $\mathrm{GnRH}$ from the anterior POA is responsible for the pituitary synthesis and release of the gonadotropins, LH, and FSH; both of which "act at a distant target, the gonads, as essential in linking the hypothalamic-pituitary-gonadal [HPG] axis" (McCarthy et al., 2017, p. 6).

Estrogen sensitivity within the MPOA defines mammalian maternal behavior across the lifespan (Champagne \& Curley, 2016) as well as multiple neural and endocrine systems, in particular, sensitivity to estrogen within the medial preoptic area of the hypothalamus (mPOA) (Champagne \& Curley, 2016; Lonstein et al., 2014). Advanced fMRI studies reveal activation in the postpartum brain areas such as the anterior cingulate and ventral prefrontal cortices, amygdala, hypothalamus, hippocampus, and septum-preoptic area. They also show "how the postpartum human brain responds to infant-related auditory or visual cues" (Lonstein et al., 2014, p. 2414).

Neural and endocrine systems likely account for maternal behavior (Champagne \& Curley, 2016). Interestingly, the human cochlea is sex-typed from an early postnatal age (Braga et al., 2019). Hearing is a sexually dimorphic trait (Shuster, Depireux, Mong, \& Hertzano, 2019; O'Hanlan et al., 2018). Response to one's infant cry and breastfeeding is associated with more significant fMRI activity in some cerebral regions (superior frontal cortex, thalamus, hypothalamus, and amygdala) (Lonstein et al., 2014). Newborn and adult females have greater hearing sensitivity and greater susceptibility to noise exposure at high frequencies (Burke et al., 2020; McFadden, 1998). Lactating mothers perceive noise differently (Lonstein et al., 2014). Could hearing differences also relate to the needs of dependent offspring and infant cues and another dimorphic trait associated with our sense of gender?

Females including pre-operative trans males are the only humans who are able to breastfeed. As we would expect, though, with variety being the norm in human development (FaustoSterling, 2018), "not all human mothers are healthy and motivated, and women are heterogeneous in their emotional and cognitive appraisals of infants" (RAZ Lonstein et al., 2014, p. 2415). Emotional and cognitive responsiveness can be modulated by other socialcognitive and socio-economic factors (Decety \& Lamm, 2006). Nevertheless, that does not subtract from the observation that many differences responsible for behaviors relevant to reproduction are lifelong and likely set in utero.

Specific essentially driven behavioral differences in the brain have been presented as limited to factors surrounding reproduction (Joel \& McCarthy, 2017; Arnold et al., 2004). The emotional behaviors most associated with mothering in females are cues of trustworthiness (Whittle, Yücel, Yap, \& Allen, 2011) and empathy (Swain, Lorberbaum, Kose, \& Strathearn, 2007), while the remainder are a mosaic (Jones \& Lopez, 2014). As discussed, women tend toward better social and linguistic skills (Reber \& Tranel, 2017; Pavlova, 2017; 
Chaplin, 2015), while men tend toward higher physical abilities combined with technical, spatial, and navigating (Pallayova et al., 2019; Tunc et al., 2016; Zell et al., 2015; Maeda \& Yoon, 2013) which are also arguably relevant to reproduction.

As we noted, overlap in the general behavioral phenotypes of males and females appears widespread (McCarthy et al., 2017); however, outside the context of reproduction and apart from physical behaviors related to reproduction, clarification of specific 'behaviors' and 'traits' has been unclear.

One offer is that "sex differences are sex-specific neuroanatomical underpinnings of some parental behaviors" established neonatally (Joel \& McCarthy, 2017, p. 380). Though the authors did not clarify what behaviors are included in 'some,' they added, "the behavior is not expressed before the appropriate activational hormonal milieu is established following mating/pregnancy" (Joel \& McCarthy, 2017, p. 380). Others claim this is unnatural, and maternal tendencies are lifelong (Champagne \& Curley, 2016), and "most adult mammals are unlikely to approach parturition with no previous parenting experience...they would have received this experience during juvenile alloparenting" and or already be multigravid parents (Lonstein et al., 2014, p. 2419).

Our theory that specific parental cognitions are biologically relevant to reproduction follows the limbic system's differential development (Zaidi, 2010; Sakata \& Crews, 2004; Kruijver et al., 2000). Furthermore, as males of all ages have substantially higher T levels than females (Smith et al., 2015; Zuloaga et al., 2009), this would include lifespan behaviors and paternal tendencies.

There is a narrative in all societies that ascribes emotion to women and aggression to men. At the risk of placing certain human behaviors into pigeonholes or a "monolithic block" (Feldman \& Lindquist, 2021), can we derive these 'certain' gendered cognitive differences from the surfeit of studies as related to the differences in the reproduction burden? We may find clues within the knowledge that human neonates are dependent on others for their survival for a very long time.

\subsection{Physical behavior}

Under the broader neo-analytic understanding gained from the feminist theory of Nancy Chodorow, we may view sexuality concerning reproduction as a universal and enduring element of the sexual division of [reproduction] (Chodorow, 1999). Reproductive sexuality is an "indirect consequence" of prenatal sex steroids that, in turn, affect the developing brain to promote sexual behavior where androphilic men and gynephilic women predominate (Bailey et al., 2016, p. 69).

This 'indirect consequence' is curious, but the existence of androphilic males and gynephilic females clarifies that sexual orientation is more dependent on the irreversible effects of early hormones than on the genetic XX/XY sex (Bailey et al., 2016). The early effect does not negate Freud's understanding of sexuality as primarily about bonding ahead of reproduction (Freud, 1966). Sigmund Freud was the first to elaborate on the primary function of sexual bonding as the path to intimacy and its secondary purpose as procreation (Freud, 1966). 
This elaboration is unsurprising in light of the developmental disconnect between bodily sex (sex) and brain sex (gender) in the Tx community discussed later.

Mothering and fathering are tethered to courtship that is tethered to mating behavior, which is, in turn, is tethered to the care of dependent offspring. As such, this broader sexuality is relative to reproductive roles, as others have both suggested (Pfaff, 2011; Owen-Blakemore, Berenbaum, \& Liben, 2009; Bartky, 1999; Buss, 1995) and implied (Reber \& Tranel, 2017).

The sexually dimorphic limbic-hypothalamic pathways in the forebrain relate to reproduction and persist unchanged throughout life, although "gonadectomy and steroid replacement have profound effects on cellular levels of sex steroid receptors" (Simerly, 2002 , p. 515). For example, one study recorded around 50\% of post-operative MtFs experienced a shift in sexual orientation to men (Gooren, 2006), which is perhaps in line with Freud's (1966) theory of sexuality.

Were both Chodorow and Freud correct? In humans, despite the myth-like belief that males seek sexual intimacy over emotional intimacy, and women the reverse, there is evidence women and men exhibited similar valence (Perrin et al., 2011), although the pursuit of the same may differ (Sakata \& Crews, 2004). "With the concealment of ovulation in humans, making sex available all the time, the human female succeeded through evolution" to put sex on display and dissociate sex from reproduction, whereby placing feminine beauty on permanent display to help "establish the pair bond and increase and maintain paternal interest and investment in any offspring" (Fathalla, 2015, p. 105). Nevertheless, the physicality of mating per see is not the topic of this article.

\subsection{Social behavior}

Social cognition may have emerged from executive functioning assisted by language.

"Affective sex differences in behavioral and physiological responses ultimately arise from differences in brain activity" (Stevens \& Hamann, 2012, p. 1579). "However, these higher levels operate on previous levels of organization, and should not be seen as independent or conflicting with one another" (Decety \& Lamm, 2006, p. 1148). Cognitive abilities are notably sexually specific (Ristori et al., 2020). Social behavior depends on sexually dimorphic circuitry in the cortex and limbic system that processes hormonal, environmental, and experiential information (Newman, 1999). The behaviors relevant to reproduction are differentially enhanced or not between the sexes by this experiential social learning (Sisk, 2016).

\subsection{Care of offspring}

Behaviors across mammalian species directed toward young offspring's care exhibit striking sex differences (Numan \& Insel, 2006). Juvenile sex-typed play, physical aggression, parenting behavior, and maze performance differ between male and female rats (Hines, 2020). Caregiving by most animals, including humans, is highly sexually dimorphic, provided by mothers, and supported by fathers. The most powerful influences on how mothers' mother and fathers father comes from their innate biology combined with their own 
experiences growing up during infant reinforcement or diminishing; these processes serve an important evolutionary role.

"Sex typical emotive behaviors would have coevolved to regulate interpersonal dynamics and enhance social fitness" (Vigil, 2009, p. 376). Empathy is a fundamental emotion in infant nurturance and caregiving (Grabowska, 2017; Swain et al., 2007). The evidence for female advantage in emotional perception and expression (e.g., recognizing emotions from facial displays) and non-verbal behavior such as smiling and gesturing is consistent (Schulte-Ruther et al., 2008), and the relevance of such an advantage to reproduction and care of offspring is unmistakable.

Hippocampus-lesioned female rhesus monkeys demonstrated significantly higher interest in infants than amygdala-lesioned individuals (Toscano, Bauman, Mason, \& Amaral, 2009). In humans, the amygdala is part of the limbic system - the emotional nervous system (Tunc et al., 2016). Considering, for example, "parental obsessions and hypervigilance for one's infant's safety, may improve infant survival and health, and promote resiliency" (Swain et al., 2007, p. 3), and, "a certain amount of heightened arousal and vigilance in this delicate balance is [also] required for infant care, which involves some anxious conduct" (Atzil, Hendler, \& Feldman, 2011, pp. 2612), "synchronous mothers show higher activations of mirror neuron and empathy-related cortical systems, which may point to greater adaptive behavior" (Atzil, Hendler, \& Feldman, 2011, pp. 2612, 2613).

Behaviors related to reproduction are recognizable in both parents in the levels of responses such as sociability, attachment, sentimentality (Stam, Huang, \& Van den Stock, 2019), aggression (Zell et al., 2015), in defend or befriend (Hoekzema et al., 2015; Sokolowski \& Corbin, 2012; McCarthy, Arnold, Ball, Blaustein, \& De Vries, 2012; Pearson, Lightman, \& Evans, 2009; Zietsch et al., 2008), instinct (Sweatt, Nestler, Meaney, \& Akbarian, 2013), and significantly in empathy (Swain et al., 2007). Others have presented similar claims (see Kolla et al., 2021; Zaidi, 2010; Decety \& Lamm 2006).

Behaviors related to reproduction where females tend to exhibit superior performance include verbal and social proficiency, emotion recognition, and empathy (Kret \& De Gelder, 2012; Kopsida et al., 2009). Women score higher and favor activity involving relationships, and men favor activity involving things, independence, spatial and mathematical skills, and aggression (as defined later) (Zell et al., 2015; Del Guidice, Booth, \& Irwing, 2012; Zaidi, 2010).

The association of empathy with parenting is strong. Empathy is "especially relevant to parenting in which infant needs are great, yet most communication is exclusively nonverbal" (Swain et al., 2007, p. 23). Females exhibit elaborate maternal behaviors to ensure their offspring's survival across all mammalian species (Fang, Yamaguchi, Song, Tritsch, \& Lin, 2018). The female focus in relationships is interpersonal. Females, more than males, are more concerned with others' opinions in social tasks and score higher on attachment, warmth, and empathy (Stam et al., 2019). Estrogen receptors in the heterogeneous MPOA of the hypothalamus are vital mediators of this behavior in mice (Fang et al., 2018). In mice, the medial amygdala has been demonstrated in sexually dimorphic control of parenting behaviors (Chen et al., 2019). 
"Sex differences in emotion processing represent some of the most robust sex stereotypes worldwide" (Whittle, Barendse, Pozzi, Vijayakumar, \& Simmons, 2020, p. 319). In disagreement, Eliot et al. (2021) report seven meta-analyses reached no consensus on differences in amygdala activation. Though consensus was not reached, it is significant to note four out of the seven studies examined reported either $\mathrm{M}>\mathrm{F}$ for activation, $\mathrm{F}>\mathrm{M}$ for negative emotion, $\mathrm{M}>\mathrm{F}$ for positive emotion, $\mathrm{F}>\mathrm{M}$ for bilateral amygdala volume. Perhaps, as the authors mention themselves, this reflects a reporting or interpretation bias common in much research. We view sex differences in emotion processing amass strong support from childhood empathy studies (see 'Empathy in Children' this paper).

Animal and human studies reveal that neural and endocrine systems likely account for the development and sensitivity of gendered parental behavior across the lifespan (Champagne \& Curley, 2016; Lonstein et al., 2014). The limbic system (the emotional nervous system), specifically the subcortical systems, including the amygdala, hypothalamus, and hippocampus, has been associated with emotion processing and motivation (Tunc et al., 2016). The limbic system zones develop differentially (Zaidi, 2010; Sakata \& Crews, 2004; Kruijver et al., 2000) and are stable across the lifespan (Simerly, 2010, 2002; McCarthy \& Konkle, 2005). Estrogen sensitivity within the MPOA governs mammalian maternal behavior and is stable across the lifespan (Champagne \& Curley, 2016). Arguably, all behaviors related to reproduction and parenting are strongly associated with the RA and parenting roles, but especially empathy and aggression (as defined later).

\section{8..6 Empathy}

In humans, differences between the sexes for emotional processing are both wellacknowledged (Kreukels \& Guillamon, 2016) and contested (Eliot et al., 2021). Intuitively, considering pregnancy and childbirth, the opportunity to express empathy is arguably greater in females.

Synchronous mothers showed greater activations in the left nucleus accumbens (NAcc), and intrusive mothers exhibited higher activations in the right amygdala. Functional connectivity analysis revealed that among synchronous mothers, left NAcc and right amygdala were functionally correlated with emotion modulation, theory-of-mind, and empathy networks.

(Atzil et al., 2011, p. 2003).

To borrow from Raz et al. (2014), does one tend to cry for, or with, another person in their time of need? In other words, do we merely understand another person is having a bad time of it, or do we feel in ourselves in response to theirs (Stuijfzand et al., 2016)? Furthermore, is it the case growing from childhood through adolescence to adulthood that one's culture teaches females to show more effective empathy than males?

An exact definition of empathy is elusive. The broad agreement says it comprises both affective (feeling similar emotions to another person) and cognitive components (understanding the feelings of another person) (Sindermann, Cooper, \& Montag, 2019). Empathy can also be defined as "appropriate perception, experience and response to 
another's emotion" (Swain et al., 2007, p. 23): It is "the ability to understand and share in the internal states of others" (Christov-Moore et al., 2014, p. 604) and "without confusion between oneself and others" (Decety \& Lamm, 2006, p. 146).

As an ancient biological phenomenon, empathy has both evolutionary and developmental precursors as an instinct involved in the care of offspring. "Evolutionary biologists suggest that empathic helping behavior has evolved because of its contribution to genetic fitness" (Decety \& Lamm, 2006, p. 1146). The evolutionary value of empathy lies in its ability to evoke altruistic motivation to see and act toward reducing another's need (Batson et al., 1981). The significance of empathy is its ability to identify and respond to another's mental state and in the care of offspring; it can respond to infant cues (Schulte-Ruther, Markowitsch, Shah, Fink, \& Piefke, 2008). The Batson et al. (1981) study participants were all adult females.

A recent mixed study of children $(N=93 ; 42$ girls $)$ demonstrated the norm for empathyrelated comforting develops somewhere between three to five years of age; and is more pronounced in five-year-olds, yet with three-year-olds showing more comforting as opposed to ignoring or laughing. Furthermore, the results demonstrated empathy in children is both an innate and acquired response. Three-year-old reported a gender difference, with girls preferring comforting to ignoring those in need (Paulus, Wörle, \& Christner, 2020). In a small mixed group study not incorporating gender as a covariate, a small group $(N=16)$ of three-year-olds highlighted how self-initiated empathy appeared as an innate and implicit mode of behavior towards peers expressing pain, sadness, being unfairly treated, or losing self-esteem (Nergaard, 2019).

Childhood gaps in empathy levels appear to increase in adolescence: this could be because of the biological (Frere et al., 2020) and social changes at this time in development. The social world of adolescent females encourages troubles talk and empathy, whereas adolescent males social world emphasizes dominance, competition (Stuijfzand et al., 2016), and sometimes association with deviant peers (Broidy, Cauffman, Espelage, Mazerolle, \& Piquero, 2003).

From a biological perspective, over time, $\mathrm{T}$ [and estrogen] levels can be considered a "trait[s]" (Smith et al., 2012, p. 12). T levels have been linked to a fall in empathy (Hermans, Putman, \& Van Honk, 2006; Cohen-Bendahan et al., 2005). A 4 - 9 fold increase in a girl's estrogen levels during puberty coincides with growth in hippocampal receptors (Goddings et al., 2014).

The Empathizing-Systemizing (E-S) theory states adult females tend to empathize, and adult males tend to systematize. Gilligan (1993) argued that males and females speak in a different moral voice; males adopt more selfish-ness, while females embrace greater selfless-ness. Gender differences in moral reasoning based on care are higher in women, while men's moral reasoning is more based on justice (Gilligan, 1993). In other words, concern for others guides women's moral compass, while men's can be more rules-based. These theories have again been supported with findings confirming "typical females on average are more empathic, typical males on average are more systems-oriented..." (Greenberg, Warrier, Allison, \& Baron-Cohen, 2018, p. 12152). This extensive $(N=671,606)$ analysis 
used an age cutoff from 16 - 89 year-olds and assumed results likely reflect a multi-factorial interaction of biology (fetal T levels) and socialization (Greenberg et al., 2018).

Psychiatrist Norman Doidge (2008), and others (Finkel, 2012; Bao \& Swaab, 2011) argue the brain itself is neuroplastic; that is, one's experiences can affect one's neural pathways. As a result,

... it is impossible to discern the degree to which group-level differences between human males and females are attributable to inborn sex factors versus social, environmental gender learning...

(Eliot et al., 2021, p. 3).

According to Doidge (2008), the only adequate explication of neuroplasticity is that every sustained neural activity changes the brain and mind - including physical, sensory, learning, thinking, imagining, cultural ideas, and activities. This is in accordance with the ability of cerebral astrocyte cells to make new synapses and neural circuits.

Such a deduction is arguably a return of Lamarckism, the idea that experience can influence one's genes and those of one's offspring (Finkel, 2012). Likewise, neural plasticity reveals increased activation of specific cortical regions after several days of empathy training (Singer \& Klimecki, 2014). Nonetheless, considering differences as taxonomic and produced regardless of how a child is raised, nurture may merely influence the average degree of innately focused difference (Sisk, 2016).

Gender and context can modulate empathy. The experience of empathy can be complicated by other social-cognitive and socio-economic factors that modulate it (Decety \& Lamm, 2006; Schieman \& Van Gundy, 2000). The motivations to avoid empathy can be many, for example, withdrawal from others' suffering to boost self-protection, material costs, and interference by others (Broidy et al., 2003). Activation of brain regions involved in empathy is significantly reduced when observed pain is has been directed at 'unfair' recipients (Decety \& Lamm, (2006, p. 1159). In comparison, affixation and social desirability can motivate empathy (see Cromwell et al., 2020; Decety \& Lamm, 2006).

The actions of others activate a human mirror system of cortical networks in the self. This automatic response may have adaptive value for individual survival. In essence, "empathy plays a central role in moral reasoning, motivates prosocial behaviors, and inhibits aggression toward others" (Decety \& Lamm, 2006, p. 1146). Data suggests these mirror systems are more highly recruited in females (Schulte-Ruther et al., 2008).

Counterintuitively, it would appear men and women activate similar neural circuitry in emotion processing, and differences in the level of empathy between males and females seem small to moderate. The reductionist conclusion is that between-group differences are hidden within-groups (Eliot et al., 2021).

Several other contributions are consistent with sex differences in empathy, both theoretical (Chodorow, 1999; Gilligan, 1993; Freud, 1966) and empirical (Hines, 2020, 2017; Swain et al., 2007; Chapman et al., 2006; Hyde, 2005). 
In line with motherly behavioral tendencies and intuition across the lifespan, newborn girls just a few hours old show more interest in human faces and more sensitivity to tactile, oral, and visual stimuli (Jones \& Lopez, 2014). This intuition is a basic, immediate, or primitive 'something' that we may see as part of the female self (Gliske, 2019) ${ }^{3}$. Although, there is the caveat that some behavioral differences could be due to differences in the different socializing of newborn boys and girls, even within the first few hours after birth (Jones \& Lopez, 2014).

The amygdala mediates empathy (Kolla et al., 2021) and empathy inhibits aggression (Decety \& Lamm 2006). In studying neural correlations of empathy in boys with conduct disorder, Polier et al. (2020) emphasized the amygdala's significant role in empathy-related emotional processing, notably, a reduction in amygdala responses in association with low levels of empathy.

Vigil's (2009) introduction of a contingency model or a "framework for understanding phenotypic variation in expressed emotion" presents sex-typical emotive behaviors coevolved "to regulate interpersonal dynamics to enhance social fitness" (Vigil, 2009, pp. $375,376)$. Generally, contingent behavior is part of social interaction. For example, the first emotive gestures, such as smiling, are produced by human neonates after face-to-face social interaction (Vigil, 2009). Very young infants show contingency between a stimulus and their response and neutral stimuli, such as blowing on baby's belly each time they jiggle their legs, and positive stimuli, such as the presence of an adult face. Contingent stimuli quickly become a trigger for smiling and cooing. The contingency is most striking with face-to-face contact with the mother, where a baby's smiling response may occur as early as the third day (Watson, 1972). In response to a baby's cry during the first few postpartum weeks, there is increased activity in both parents' limbic brain regions (Swain, 2007).

Levels of empathy are dependent on many factors, including genetics, age, education, income, and relationship status. Self-reported empathy in men and women always appears more significant in women; however, the gender gap closes in older age. Nevertheless, empathy levels do not begin to drop significantly until age fifty (Schieman \& Van Gundy, 2000). So, of course, a mother's empathy would be independent of her age, whether in her adolescence or her fifth decade. Concerning mothering, females are better at detecting expressions (LoBue \& DeLoache, 2009), and a mother must resonate with the state of her infant's helplessness, meaning she must possess empathy and maternal synchrony (see Atzil et al., 2011).

Females are hardwired for empathy and emotion recognition (Zaidi, 2010). Moreover, females exhibit higher rates in simple forms of empathy; contagious crying, neonatal imitation, social referencing. The different empathy patterns remain stable or grow larger with age (Christov-Moore et al., 2014). Across development, females appear to be especially sensitive to perceived interpersonal threats. For example, studies report sex differences in startle response to social cues that imply the potential of interpersonal threats. Females show a greater tendency toward more substantial startle potential (McClure et al.,

\footnotetext{
${ }^{3}$ Since retracted by the publisher.
} 
2004). The key phrase here is 'across development.' Interestingly, women who engage in crime do so more to protect relationships (Broidy et al., 2003).

Emotion expression evolved to regulate exploitation and anti-exploitation defenses and acquire reproductively relevant resources, cooperative resource-acquisition strategies. As a founder of the field of evolutionary psychology, David Buss, expressed:

Women may express an emotion of sexual desire to deepen a committed relationship in one context, or to expropriate a man's resources.

Displays of anger or masculine prowess may signal reciprocal resource capacity but may also convey to would-be exploiters that one is a poor choice as a potential victim of exploitation.

(Buss, 2009, p. 392).

Consistent with results in several previous studies on empathy (females $>$ males) and autism, a large study of online participants $N=1098$ (304 males), average age 21.94 years, females scored higher on all scales measuring empathy. Additionally, for autistic and systemizing tendencies, males $>$ females (Sindermann et al., 2019).

An fMRI investigating gender-related differences in brain regions supporting empathy reported regions involved in the human mirror neuron system (particularly the inferior frontal gyrus and Brodmann's Area) are recruited during emotional perspective-taking in both males and females. However, activation is more substantial in females in the right inferior frontal gyrus and right superior temporal sulcus (Schulte-Ruther et al., 2008). Their finding follows previous reports about differences between the sexes in the lateralization of brain functions (see, for example, Cahill et al., 2004).

By directly comparing meta-analytical literature of fMRI and positron emission tomography (PET) neuroimaging for women and men's emotional and neural responses to the same positive and negative stimuli, regional activation differences were noted notably in the amygdala and hippocampal activation. As well, sex differences favoring women were observed for negative emotion, with less activation in men on the same negative stimuli. The converse was noted for both sexes for positive emotion (Stevens \& Hamann, 2012). These results parallel other findings from the behavioral and psychophysiological literature on substantial sex differences (Yang et al., 2018; Zell et al., 2015; Heberlein, Padon, Gillihan, Farah, \& Fellows, 2008; Swain et al., 2007), including response to fear (Zell et al., 2015).

Inter-regional crosstalk is something in which females appear to excel. One contemporary DTI connectivity study concluded that during development, within-hemisphere (intrahemispheric) connectivity typifies male brains with networks that are transitive, modular, and discrete, whereas inter-hemispheric connectivity and greater cross-hemispheric participation typifies female brains. The study included a DTI of 948 subjects aged 8-22 (mean age males 14.9, females 15.1 years). The authors claim this as overwhelming support for the hypothesis that male brains are heightened for intra-hemispheric communicating and female brains for interhemispheric communication (Ingalhalikar et al., 2014). 
These results were supported further in another large study that showed Female $>$ male connectivity within sensorimotor and visual cortices and "some evidence for male $>$ female connectivity in sensorimotor and visual cortices" (Ritchie et al., 2018, p. 2970). Although participants' age was anywhere from 'young' to $70+$, the evidence shows that some sensory and cognitive aspects differ between the sexes, with male brains more asymmetrical and female brains more bilaterally organized (Grabowska, 2017).

The mixed results so generally problematic in sex and gender difference research could be better interpreted by moving from a single brain to a multi-brain frame of reference. The notion that inter-regional crosstalk may increase as individuals become empathically engaged (Raz et al., 2014) is promising. The study by Raz et al. (2014) claimed unique evidence for activity between multi-factorial circuits or inter-regional crosstalk as the neural bases of empathy and the interaction of these circuits with subcortical limbic structures during the intensification of empathic engagement, which is also context-dependent. In terms of reproduction, context-dependent does not equate with an insignificant difference. The Raz et al. (2014) study participants were all adult females and having lived a substantial number of years would typically be regarded as a confound, would instead plausibly account for developmental differences due to socialization and opportunity to empathize.

Though empathy activates equal brain regions in males and females, there is the possibility there are reliable male/female differences in specific populations under particular conditions (Eliot et al., 2021). This statement could, without doubt, be related to childbirth and the rearing of infants. Nonetheless, it is not pertinent to claim differences in empathy levels, whether innate, learned, or both, are irrelevant sex differences in behavior at any age.

Overall, the evidence suggests there are stable differences in empathy levels across the lifespan relevant to reproductive behavior and care of offspring.

\section{Empathy in Childhood}

Subcortical and limbic brain regions are crucial elements in emotional processing (Hahn et al., 2015). The amygdala is a critical element in emotion perception and processing (Pallayova et al., 2019). This region has also been shown to be sexually dimorphic (Pallayova et al., 2019; Lotze et al., 2019; Reber \& Tranel, 2017), and its nuclei have connections to other limbic areas (Crestani et al., 2013; Bonelli \& Cummings, 2007).

Sex differences in human behavior are expressed in the first few post-natal days. Female neonates and young girls prefer looking at human faces, while male infants look more at mechanical mobiles (LoBue \& DeLoache, 2009; Connellan, Baron-Cohen, Wheelwright, Batki, \& Ahluwalia, 2000).

Day-old neonates demonstrate sexual dimorphism in both social and mechanical perception. Male infants show a more substantial interest in mechanical objects, while female infants show a more substantial interest in the face. The male preference could not merely be for a moving stimulus, as both stimuli moved.

(Connellan et al., 2000, p. 116). 
"The evidence linking early testosterone exposure to sex-typed play is particularly robust" (Hines, 2020, p. 37). Toy preference, faces versus things, and play preferences in children are apparent as early as age six months (Kung, Li, Golding, \& Hines,. 2018; Berenbaum \& Beltz, 2016; Jones \& Lopez, 2014; Alexander, 2003) and all with scant social experience.

"...parents do not have to coerce or coax boys to play with toy weapons, and parents do not have to force or teach girls to play with dolls" (van der Dennen, 2005, p., 3). It is also possible "that boys like toys that can be moved in space" (Hines, 2011, p. 74).

Studies with monkeys bearing similar results highlight how toy preferences cannot be explained simply by social pressure (Bao \& Swaab, 2011). Overall, it seems that gender identity, sexual orientation, other behaviors, and brain disorders are programmed prenatally as dimorphic in the brain (Bao \& Swaab, 2011).

In a study of $5-11$ year old's empathy and systematizing, $\mathrm{F}>\mathrm{M}$ on the empathy quotient and $\mathrm{M}>\mathrm{F}$ on the systemizing quotient. This result suggests different brain types are present at an early age (Auyeung et al., 2009). In a small study of 4-year-olds indicative of fetal testosterone effects on development, girls demonstrated a better quality of social relationships (Knickmeyer, Baron-Cohen, Raggatt, \& Taylor, 2005).

In a more extensive study $(N=70)$ of one-year-olds and matching fetal testosterone to infants, girls made more eye contact than boys suggesting an inverse relationship between fetal testosterone levels and eye contact. Lutchmaya, Baron-Cohen, \& Raggatt, 2002). Eye contact has previously been associated with sociability (Baron-Cohen, O'Riordan, Jones, Stone \& Plaisted, 1999).

The expression of empathy at an early age is indicative it is not merely a learned behavior as sometimes proposed.

\subsection{Aggression}

The primate family that includes humans, Hominidae, is characterized by larger males than females, robust bodies, well-developed forearms, and have no tails. High levels of male-onmale aggression further characterize them, and aggressive behavior has been essential in the human evolutionary past (Carrier, Schilling, \& Anders, 2011). Given male-on-male and intergroup aggression in the past and present Anthropocenes in competition for resources, including females and reproduction (reproductive fitness in Darwinian terms), it is possible natural selection for aggressive behavior in males was one factor influencing the evolution of a larger muscular-skeletal system (Carrier, Schilling, \& Anders, 2015).

Aggression is also widely accepted as having two forms - direct or overt, and indirect, covert, or social. Direct aggression encompasses direct verbal or physical confrontation, whereas indirect aggression uses social means such as gossip, character attacks, rumormongering, rejection or exclusion, and manipulation of peer relationships (Card, Stucky, Sawalani, \& Little, 2008). In childhood, boys lean toward physical aggression while girls lean toward social aggression (Li et al., 2020; Ligthart, Bartels, Hoekstra, Hudziak, \& Boomsma, 2005). 
"Sex is among the strongest correlates of criminal offending" (Broidy et al., 2003, p. 503). The discrepancy in levels of direct contemporary aggression between men and women remains striking.

Men are more likely to show physical aggression. They commit $89 \%$ of all murders and $99 \%$ of all sexual crimes, while women are more likely to engage in acts of indirect aggression: spreading vicious rumors, gossiping, or fabricating stories about that person.

(Bao \& Swaab, 2011, p. 220).

A dominance of testosterone around birth and at about nine weeks of gestation results in masculinization of the brain and genital tract (Zuloaga et al., 2009; Wizemann \& Pardue, 2001), and males of all ages, including prenatally, have substantially higher T levels than females (Lonstein et al., 2014). Accordingly, there is strong evidence for sex differences in the sympatho-adrenal nervous system's neural control (Hinojosa-Laborde et al., 1999). At rest, plasma noradrenaline (norepinephrine) levels are consistently higher in females and adrenaline (epinephrine) levels higher in males (Davidson, Vandongen, Beilin, \& Tunney, 1984), and men and women react differently to stress, both psychologically and biologically (Kret \& De Gelder, 2012). Findings from neuroimaging record response patterns to stress in the HPA axis and sympathetic nervous system differ markedly between males and females. Female sex hormones lessen the sympatho-adrenal and HPA responsiveness. Sex differences in stress response are portrayed by 'fight-or-flight' in men and 'tend-and-befriend' in women" (Verma et al., 2011). The amygdala region is broader in ciswomen with a higher estrogen density than androgen receptors (Halpern, 2013). Furthermore, as we saw, the amygdala mediates empathy (Kolla et al., 2021) and empathy inhibits aggression (Decety \& Lamm 2006).

Gender differences in stress hormones noradrenaline and adrenaline support the view that estrogen reduces sympathetic activity and cortisol and adrenaline secretion. "Control of sympatho-adrenal function is different in females, and responses vary during the menstrual cycles" (Hinojosa-Laborde et al., 1999, p. 122). "The gender differences in noradrenergic neurotransmission may protect females against [hyperactive] sympathetic responses" (Hinojosa-Laborde et al., 1999, p. 122).

In support of the hypothesis that prenatal biology influences post-natal social behavior, fetal testosterone levels in typically developing children measured via amniocentesis and compared to their infant levels (age range 6-9 years) revealed a strong inverse correlation with empathy scores for males (Chapman et al., 2006). Empathy is higher on average in females than in males and appears to be reduced by fetal testosterone exposure (Hines, 2011). Unsurprisingly, psychopaths exist across all cultures and ethnic groups, and psychopathy occurs more frequently and typically more violently in men (Wynn, Høiseth, \& Pettersen, 2012). Psychopaths have an apparent dysfunction in empathetic response (Ali, Amorim, \& Chamorro-Premuzic, 2009). Structural and functional magnetic resonance imaging (MRI) has revealed psychopathy, and some biological processes in the brain are linked. Core psychopathic features are associated with frontotemporal regions and 
frontotemporal, limbic, paralimbic, and cerebellar structures (Johanson, Vaurio, Tiihonen, \& Lähteenvuo, 2020).

Human babies have an extended juvenile period. Care of such dependent offspring requires teamwork from parents that subsumes attachment, suckling, emotional nurturance, and parental sensitivity to danger (Christov-Moore et al., 2014). For primitive fathers, aggressive behavior was social conduct essential in competition for food, territory, and mating (Gouveia et al., 2019). For contemporary fathers, the care of offspring may also involve physical aggression in the forms of territorial defense and acquisition of resources (Meyer-Bahlburg, 2019), i.e., the view of aggression outlined below. Human babies and their mothers require security and support in resources for many years before they are considered mature, and a partnered father must resonate with the state of his family's needs.

The neural network components that regulate aggressive behavior include the amygdala, the hypothalamus, the putamen, and the orbitofrontal cortex (for review, see Gouveia et al., 2019; Unger et al., 2015). As a master regulator, T plays a significant role in the arousal of brain centers involved in aggression and the muscular system's development that enables aggression's realization. It acts through the interplay between subcortical structures in the amygdala and the hypothalamus (Unger et al., 2015; Batrinos, 2012). Gonadal steroid levels are increased in a sex-specific manner. During the fourth to the fifth month of pregnancy, a surge of fetal T occurs lasting a few weeks (Hines, 2020) to reach adult levels that inundate the male brain inducing anatomical and organizational changes (Batrinos, 2012).

Post-natally, T levels peak in boys at 1-3 months of age and decline at six months of age (Kuiri-Hänninen, Sankilampi, \& Dunkel, 2014) until puberty. T levels in adult males, i.e., after physical development, average 10 - 20 times higher than adult females (AACB, 2020). Higher T levels for women are associated with lower maternal behavior (Smith et al., 2015). Girls with congenital adrenal hyperplasia $(\mathrm{CAH})$ show more aggression than non-affected siblings (Cohen-Bendahan et al., 2005).

Further, male empathy levels appear to be reduced by the higher $\mathrm{T}$ exposure in-utero (Hines, 2017), and men with lower $T$ levels demonstrate increased parental responsiveness (Lonstein et al., 2014).

In reply to criticism of her book Testosterone Rex (2017) and her analysis of distorting effects of assumptions about sex differences, Cordelia Fine suggests hundreds of studies mistakenly claim differences in prenatal T hardwire gender identity (Fine, Joel, \& Rippon, 2019). That suggestion is in stark contrast to observations that in the final periods of fetal development, the masculinization and defeminization processes of the hypothalamus are dependent on T secretion (Acevedo-Rodriguez et al., 2018). Similarly, males of all ages have substantially higher T levels than females (AACB, 2020), or that during early pregnancy, a surge of fetal $\mathrm{T}$ reaching adult levels occurs in the male fetal brain (Batrinos, 2012).

It seems some brain disorders are programmed prenatally as dimorphic in the brain (Bao \& Swaab, 2011), though likely along a spectrum of expression and responsiveness as every other disorder. Aggression is a prominent feature in many children with 
neurodevelopmental disorders. Aggression is more highly associated with boys in adolescence. Perhaps further insight into T's sex-specific effects can be better inferred from sex-related disorders in young subjects (Negri-Cesi et al., 2004) and twin studies.

T's early effects are highlighted in the study of same-sex (SS) and opposite-sex (OS) 16year-old twins. OS girls (girls from boy/girl twin sets) showed a more masculine behavior pattern than SS girls (girls from girl/girl twin sets) with no differences in T levels or pubertal status. The twin study supports T's prenatal levels as higher for OS girls and adds backing for sex differences in aggression overall, similar to $\mathrm{CAH}$ girls who show more aggression than non-affected siblings (Cohen-Bendahan et al., 2005). In contrast, studies reveal CAH girls "do not differ from other girls in spatial ability, verbal ability, language lateralization, handedness, or aggression, but may prefer "boy toys" as children and later have decreased sexual interest in men" (Erickson-Schroth, 2013, p. 159).

The coupling between cortisol, dehydroepiandrosterone (DHEA), and testosterone are potential mechanisms for destructive behavior in $N=50$ extremely antisocial adolescent males (mean age 16.08 years). An end-product of the HPG axis is T secreted by the testes (Johnson et al., 2014). In the HPA and HPG axes, these hormones have common effects in moment-by-moment response to stress, for example, momentary fluctuations in cortisol, testosterone, and DHEA. The abnormal functioning of these hormones may be related to destructive behavior. The authors suggest "HPG-axis functioning could be so powerful that it recruits the HPA...to operate in an androgenergic manner leaving afflicted individuals with the biological potential for socio- psychopathic behavior (Johnson et al., 2014).

Across all mammalian species, "aggression is a fundamental means to defend territory, compete for mates and food, and protect offspring" (Wong et al., 2016, p. 593). In humans, aggressive behavior is social conduct typical of ancient Anthropocenes, where it was essential in the competition for food, territory, and mating (Gouveia et al., 2019). War in traditional societies required individual striving and centered on reproductively essential resources. It has been argued that lethal conflict arose in the evolutionary context of reproductive striving. Under this view, reproductive competition in warfare can be seen as a significant evolutionary selective force waged in the name of women, bridewealth, revenge, food resources, and territory (Low, 2015).

While empathy training exists (Singer \& Klimecki, 2014), aggression, and not empathy, can be formally studied to Ph. D. level in the form of 'War Studies' (Kings College, London). Males score higher than females on measures of aggression (Hyde et al., 2018) and spatial processing [resource attainment] (Reber \& Tranel, 2017; Hyde, 2005). Moreover, the difference's magnitude is the largest favoring males in situations with the most danger (Hyde, 2005). In mice, the ventromedial hypothalamus is more responsive to males' presence than to females. This response may play a role in male aggression (Wong et al., 2016).

The substantial contemporary differences between a human female and male response in the amygdala to perceived threats of aggression may further support the role of aggression (under another name), or rather its absence, in parenting. 
A species' future rests with "the ability of its members to coordinate behavioral responses with physiological processes in response to sexually relevant cues" (Simerly, 2002, p. 508). Within the framework of evolutionary theory, who reproduces best, survives (Low, 2015). Testosterone levels in males of the modern Anthropocene remain high (AACB, 2020), and males are still more likely to exhibit higher visuospatial and navigational skills and direct aggression (Kopsida et al., 2009). Male behavior in modern warfare suggests that the 'band of brothers' even now exists, as do the correlations of war as a play for resources, aggressive behavior, and rape (Low, 2015).

\subsection{Aggression in Children}

There can be no doubt direct aggression in childhood exists and cannot be regarded as a learned behavior. Boys tend to enact more direct aggression than girls (Card et al., 2008). The expression of indirect aggression, on the other hand, is similar between boys and girls with trivial differences in magnitude and with the two types more intercorrelated in boys (Card et al., 2008).

As children age, they increase their social skill levels, and more sophisticated approaches to aggression become possible. Nonetheless, social aggression increases drastically at about age 11, especially in girls, and is arguably a learned skill. Empathy and social intelligence co-create each other. As girls mature, they become more outstanding in social intelligence and, due to their lower muscular strength, rely more on indirect aggression (Björkqvist, 1994).

This outcome is in accordance with girls and women's response to a threat with 'tend and befriend' rather than 'fight or flight' (Verma, Balhara, \& Gupta, 2011).

In a study of 14-year-old twins focusing on relative life-naivety, aggression is a prominent feature in many children with neurodevelopmental disorders. Across their entire sample, aggression was positively associated in male children and increased putamen volumes (Yang et al., 2017).

Moreover, aggression is a highly hereditary and stable trait across all ethnicities, cultures, and age groups (Ligthart et al., 2005). Children with early-onset conduct disorder show severe levels of aggression (von Polier et al., 2020). Decreased functional activity in the putamen was significantly associated with physical aggression in a study of $9-12$ year-olds (Li et al., 2020).

A large genomic study of empathy in 7-8 year-olds could not locate any apparent genebased association with emotion recognition or its development. The authors did report the significant association of one gene on chromosome 17 with the development of autism spectrum disorder in males as evidence for caution in interpreting their results. They stated their results are not easily interpretable and call for further research using standardized study designs and methods (Woodbury-Smith, Paterson, Szatmari, \& Scherer, 2020).

In contrast, a study of antisocial behavior in 11 - 13 year-olds (223 males) adjudged for sex, age, and cranial volume found an association with callous-unemotional traits and amygdala hypoactivity with significant differences $\mathrm{X}$ sex $\mathrm{X}$ traits $\mathrm{X}$ brain hemisphere interaction. The 
authors concluded a neurodevelopmental basis to these characteristics in children (Ling et al., 2020).

\subsection{Aggression by another name}

All forms of aggression - direct, indirect, reactive, proactive - can be adaptive (competitive) or maladaptive (Orobio de Castro, Merk, Koops, Veerman, \& Bosc, 2005). Following Hare (2017) and Huber and Kravitz (2010), contemporary aggression can be regarded as a distant cousin to traditional aggression and can be viewed more helpfully, less aberrant, and more positively as heroics or a competitive spirit related to mate selection, supply and defense of resources, self-defense, and defense of significant others.

A philosophical view of aggression presents masculinity as manifesting itself in cruelty and violence, where no peace negotiations or arguments in favor of tolerance can decrease its intensity (Weigel, Vodolaga, Shapoval, Kartashova, \& Safronenko, 2020). Within the 21stcentury Anthropocene, such aberrant masculinity is non-essential (Meyer-Bahlburg, 2019). Nonetheless, aggression has not yet evolved out of our species, perhaps simply because aggression is nowadays aligned more positively with 'heroics, a competitive spirit related to mate selection, supply and defense of resources' etcetera, as Huber and Kravitz (2010) proposed. While the defining characteristic of the human domestication syndrome is dampened reactive aggression, i.e., a decrease in physical aggression and fear (Hare, 2017), unfortunately, as with all human behaviors, some individuals and societies misuse their natural tendencies.

A contemporary notion of aggression understands it as a competitive spirit alongside a willingness to mount violent defenses against outsiders signifying a kind of natural selection for friendliness and characteristics that enhance mating ability, survival, and reproductive success (Sunstein, 2020).

\section{In sum}

Criticisms that science has historically studied humans who have already lived large parts of their lives, then generalized results and separately pigeonholed many male and female behaviors is justified. Additionally, "Biology has [often] been used to subjugate and suppress the rights and experiences of women and other marginalized groups (Feldman \& Lindquist, 2021). Nevertheless, to study only life- and treatment-naïve participants would likely also be a disservice. So a biologically reductive narrative is appropriate given certain behaviors are necessary for the reproduction of the species.

Prenatal development is arguably a period when the fundamentals of gender as precognitions relative to reproduction (presented herein) are laid down. These cognitions are specifically tethered to reproduction and care of offspring. Reproduction of our species demands differentiation in the physical and psychobiological care of offspring. After heterosexuality, the two most notable differences in cognitive behaviors discussed here occur concerning offspring's care as empathy and aggression. 
Post adolescence, sexually dimorphic courtship is tethered to sexually dimorphic mating behavior, which is tethered to sexually dimorphic Mothering and Fathering, which is, in turn, tethered to dimorphic roles in the care of offspring. We present these differential networks as reflected in the specific behaviors relevant to reproduction stemming from the

RA. The higher levels of empathy shown by females are likely the 'why women mother' that Chodorow was missing (Chodorow, 1999), whereas fathers predominate in other parental areas.

This article presents the emergence of a subconscious awareness of this reproductive axis as gender. The strength of any sexual dimorphisms related to gender incongruence may not be homogenous and may also be located in one, some, or all RA regions along a spectrum (see later).

\section{EXEGESIS FROM SEX / GENDER INCONGRUENCE}

As a reproductive axis must exist in Tx and non-heterosexual individuals alike, it would be remiss or deemed transphobic to focus on gender identity without engaging the research into sex/gender diverse communities.

\subsection{Timing is everything-Neurogenesis and Corticogenesis}

Neurogenesis is sequential, and corticogenesis, in particular, is time-sensitive neural development. The sequential birth of different cell types is known as 'temporal patterning,' an evolutionary strategy generating neuronal diversity. "The cerebral cortex is intimately linked with temporal patterning" (Rossi, Fernandes, \& Desplan, 2017, p. 7). The early brain develops sequentially. Two to three weeks after conception, folding and fusion of ectoderm create the primitive neural tube of the CNS (Marsh, Gerber, \& Peterson, 2008).

When the gonads are developed at around the end of the seventh week, bodily sex is determined, while other parts of the reproductive system are still bipotential (Tasopoulos, 2018). The head is almost as large as the rest of the embryo's body by the eighth week (OpenStax, 2016), and stem cells differentiate into sensorimotor regions of the cortex and significant midbrain components regions and the spinal column for division into cortical and subcortical neurons (Marsh et al., 2008). For example, DTI of 13-week old post-mortem fetal brains reveals limbic neural tracts as major tracts (Huang et al., 2009).

By the tenth week, the fetal stage begins when a developing embryo establishes the rudimentary structures of all of its other organs and tissues (Stiles \& Jernigan, 2010). During the perinatal period, fetal hormones activate and organize the neural substrate (Menger, Bettscheider, Murgatroyd, \& Spengler, 2010). Perinatal testosterone levels organize fetal male and female brains differently (Jones \& Lopez, 2014).

Notably, the fetus is anatomically organized, differentiated, and producing sex hormones before neurogenesis is complete, and these same hormones exert their activational effects on the developing brain (Luine, 2014; Bao \& Swaab, 2011; Savic, Garcia-Falgueras, \& Swaab, 
2010). This temporal and physical displacement of body and brain developmental processes means it is possible for the "sex of the genitalia" and "brain gender identity and sexual orientation" to become discordant (Tasopoulos, 2018) or incongruent (Roselli, 2018). In other words, the development of body and brain phenotypes are temporally displaced; specifically, (body) sex is developed before the CNS development is complete (Swaab, 2007).

\subsection{The trans community}

With the recent claim that the human brain is not sexually dimorphic nor lies along a spectrum, Eliot et al. (2021) claim that "popular discourse about the 'male brain' and 'female brain' as clearly distinct" has been disproved (Eliot et al., 2022, p. 80). This claim has the potential to delegitimize the validity of the Tx communities and especially of persisting Tx children. We would prefer to offer another position.

The reproductive axis is common to cis and Tx identities, making the Tx community another candidate in examining neural subsystems as the source of gender identity.

Research has presented a considerable collection of genetic and hormonal factors that may lead to gender issues (Swaab \& Garcia-Falgueras, 2009), though the word 'problems' here is unfortunate. Nonetheless, the origins of the Tx identities and non-heterosexuality are far from fait accompli (Roselli, 2018).

By age two to three, most children have an awareness of their gender (Ahmed, Morrison, \& Hughes, 2004), and most without issue. A very few, on the other hand, feel a sense of unease. We now refer to distress resulting from this unease as gender dysphoria (GD) (Sánchez \& Vilain, 2013). Late-onset gender dysphoric individuals whose earliest memories are filled with similar unease yet not acted upon until later adulthood mechanisms come into play. The mechanism here is also unclear.

What is most relevant to our hypothesis is not what causes sex and gender diversity, but where and what is it Tx people of all ages feel is inconsistent with their biological sex? What is it many children identify as their gender as early as age two (Zucker, Bradley, \& Sanikhani, 1997), or age three (Olson \& Gülgöz, 2018; Hewitt et al., 2012)? If there is no internal biological locus for gender identity, what is it very young and persisting adult Tx individuals feel inconsistent with their bodily sex? What is the dysphoria apprehended by late-onset individuals?

If gender is an entirely social construct, all hair, and makeup, as has been implied (Rippon, 2017; Butler, 1990), age six months to five years seems insufficient time to learn the political and socio-cultural structures of gender without some prior form of influence, namely in utero.

Across studies in Tx populations, hints of a developmental disconnect between bodily sex (sex) and brain sex (gender) are apparent. This disconnect led us to question what and where is it Tx individuals feel is inconsistent with their biological sex? How can this disconnect exist before very young Tx children absorb cultural and social influences? 
Intense pre-pubescent dysphoria persisting into adulthood is an essential DSM V requirement for the diagnosis of GD.

A brief review of research into this broad topic provides as yet unconfirmed evidence for cause and or consequence of gender incongruence, including genes, epigenetics (Fernandez et al., 2020, 2018; Arnold, 2017; Ngun, Ghahramani, Sánchez, Bocklandt, \& Vilain, 2011; Jones \& Lopez, 2014), hormones, Menger et al., 2010), neuroanatomy and function (Beking et al., 2020; Mueller, Landré, Wierckx, \& T'Sjoen, 2017; Kreukels \& Guillamon, 2016; Burke, Manzouri, \& Savic, 2017; Luders et al., 2009; Rametti et al., 2011; Savic \& Arver, 2011), and environment (Tozzi et al., 2019; Gräff, Kim, Dobbin, \& Tsai, 2011). As yet, none are conclusive.

However, it does appear that differences concerning body sex, gender identity, and sexual orientation differ neurologically, both structurally and functionally, indicating these traits develop independently (Roselli, 2018). Trans studies alone do not locate gender; nonetheless, our biological location of gender highlights the multifactorial basis for gender identity and how various factors could be a part of the gender network within the regions of

the reproductive axis. For example, estrogen's actions on the developing hippocampus, cortex, cerebellum, hypothalamus, and amygdala are generally permanent and range from the establishment of dimorphic sex differences to generalized effects (Fernandez et al., 2020). As we saw, T's actions "in the final periods of fetal development are fundamental for the processes of masculinization and defeminization of the hypothalamus" (AcevedoRodriguez et al., 2018, p. 11). T plays a significant role in the brain centers' arousal of behavioral manifestations (Unger et al., 2015).

Increasing $\mathrm{T}$ levels in adolescence that show a marked rise in boys and an early plateau in girls is related to amygdala volumes. As we saw, a $4-9$ fold increase in a girl's estrogen levels during puberty coincides with growth in receptors in the hippocampus (Goddings et al., 2014).

\subsection{Trans identities in brief}

TBV of the Tx population matches that of their birth-assigned sex (Manzouri, Kosidou, \& Savic, 2017; Hoekzema et al., 2015). Likewise, TBV has consistently been shown to be sexually dimorphic (Eliot et al., 2020). However, it is a distraction to state brain volume, GM, and WM are merely scaled to the rest of anticipated body morphology and claim they are unrelated to gender identity or behavior.

"The theory of the origin of transsexuality is based on the fact that the differentiation of sexual organs appears well before the sexual differentiation of the brain" (Bao \& Swaab, 2011, p. 217). Fetal somatic and neural development are temporarily displaced; they develop in two separate sequential processes. During the first trimester, the body is sexed with one set of genetic and hormonal triggers (Ellis \& Ames, 1987; OpenStax, 2016), while the brain is gendered during the second and third trimesters with a second set of hormonal triggers (Tasopoulos, 2018; Menger et al., 2010). 
This temporal displacement and or effects on other neurological structures may be implicated in the origins of Tx identities. This implication is supported by sex reversal in the BSTc and INAH3 regions of the hypothalamus in Tx individuals (Smith et al., 2015; Bao \& Swaab, 2011).

However, this factor alone cannot be used for early diagnosis of transsexuality because sex difference in BSTc volume is not apparent until early adulthood (Bao \& Swaab, 2011), making it possible that the differences are not a cause of transsexuality but rather a result (Chung, De Vries, \& Swaab, 2002). Differences in the BSTc are more likely the result of a life lived (experience) rather than causing gender diversity (Hines, 2020).

Furthermore, the effects of estrogen or androgen treatments for the changes in the hypothalamus of trans individuals cannot be discounted (Guillamon, Junque, \& Gómez-Gil, 2016; Pol et al., 2006). Consensus on the significance of the INAH3 to behavior and identity remains lacking (see Eliot et al., 2021). Despite the current lack of consensus and replication in Tx studies, it may be productive to consider other cerebral networks to investigate the processing of own body perception (Savic \& Arver, 2011).

\subsubsection{Body perception}

The perception of one's body and one's self (Samuels, 1986) "heavily involves cerebral midline structures incorporating a parieto-occipital 'body detection' network" (Manzouri et al., 2017, p. 1005). Disruption of the genetic programming of fronto-parietal and limbic circuitry may be a prime mechanism underlying a variety of social disorders such as schizophrenia and attention deficit hyperactivity disorder (João \& Filgueiras, 2018; Sokolowski \& Corbin, 2012; Jia et al., 2009) and autism spectrum disorder in both the MtF and FtM Tx communities (Thrower, Bretherton, Pang, Zajac, \& Cheung, 2020; Jones et al., 2012; Hines, 2011; De Vries, Noens, Cohen-Kettenis, van Berckelaer-Onnes, \& Doreleijers, 2010). The conclusion from a recent small study of 34 early onset treatment-naive FtM and 21 early onset treatment-naive MtF participants was the interaction between [neural] networks accounts for gender variant differences and is key in building a sense of gender. The authors report their data confirm the implication of the fronto-parietal network postulated by the own's body perception hypothesis, particularly between the right and left frontoparietal regions (Uribe et al., 2020). It appears Tx individuals are "unable to incorporate typical body characteristics of their gender assigned at birth into their own body representation in the brain" (Fisher et al., 2020, p. 2). Frontoparietal disconnection has been implicated in gender incongruence and dysphoria (Feusner et al., 2017; Burke et al., 2017). GD individuals differ concerning connectivity within networks involved in self-perception and own-body identification (Majid et al., 2020; Feusner et al., 2017).

Again, and following on from the understanding that any distinct region of the CNS is unlikely to serve as the entire neurobiological location for gender in the cis-gendered, the biology of gender incongruence with or without dysphoria would require consideration of other critical regions. 


\subsubsection{The importance of treatment naivety}

There remain confounding issues in Tx research, and Tx studies have faced many confounding issues (Fine, 2020; Hyde, 2005). Confounds include - the scant number of MRI studies; a mix of non-heterosexual and heterosexual subjects; small numbers of agematched studies; a scarcity of early-onset studies compared to later onset where no allowance is made for the variety of years already lived; the use of post-mortem studies, and age-unmatched post-mortem studies. Any Tx research that does not incorporate these appropriate exclusion and inclusion criteria makes it very difficult to establish cause and effect.

It would seem imperative that inclusion criteria of the early age of onset and pre-treatment (hormone naive) are particularly crucial in identity studies, so the studies reviewed here all qualify for these inclusion criteria. The research outcomes presented here highlight the different biology of gender, its similar location within the reproductive axis to the cisgendered, and its disconnect in the Tx community.

The Tx community literature has been disparate and conflicting, often confounded by outcomes in hormone-treated and treatment-naive subjects (Smith et al., 2015). Therefore, we consider it imperative for our review into the FtM Tx population that only studies of hormone naïve Tx can be considered relevant.

\subsubsection{Cortex - PFC}

In early-onset (treatment-naive) FtM and MtF individuals, gross brain morphology in various areas such as cortical thickness, white matter microstructures, ER $\alpha$, and ER $\beta$, suggests their atypical or multifaceted brain sex development (Fernandez et al., 2018; Rametti et al., 2011). Despite a wide variety of studies with sparse replication in twin studies (Smith et al., 2015), cross-sex hormone treatment has been associated with changes in cortical thickness and cortical and subcortical volumes (Rametti et al., 2011), though that study was underpowered ( $\mathrm{MtF} N=18$ with 38 controls). Further studies report different cerebral connectivity profiles of female-to-male (FtM) and male-to-female (MtF) subjects compared to cisgender controls. Concerning subcortical structures, the GM volume of the right putamen of MtFs was in the female range (see in Kreukels \& Guillamon, 2016).

\subsubsection{Hippocampus}

Hormone naive FtM Tx individuals follow natal female hippocampal differences (Manzouri et al., 2017). In Tx individuals, the amygdala and hippocampus develop with size and neuron numbers closer to the desired rather than natal sex (Smith et al., 2015).

\subsubsection{Amygdala}

Hormone naive FtM subjects display female-type connections within the amygdala (Manzouri, et al., 2017). Amygdala volume in MtF subjects is consistent with their sex at birth, not their gender identity (Mueller et al., 2017), highlighting the disconnect between

size and connectivity. 


\subsubsection{Connectivity / Connectome}

An in vivo brain imaging review covering the entire structural and functional literature in people with gender incongruence and with exclusion criteria for prior hormone therapy, including the contraceptive pill, concluded that most local physiological aspects of gender identity in Tx individuals had undergone a biological transition (Hahn et al., 2015).

The genetic milieu contributing to gender identity may be completely different from one individual to the next. While, in some individuals, a single genetic variant may be sufficient to result in gender dysphoria, it does not follow that that variant would be necessary or sufficient to cause gender dysphoria in the population at large.

(Theisen et al., 2019, p. 8).

As was noted previously, the strength of sexual dimorphism in the cisgendered is likely homogenous across all of the RA. Simultaneously, the pattern for causes of incongruence in the Tx community suggests sexual dimorphisms may be heterogeneous, i.e., any or many, leading to many phenotypes across a spectrum of expression. Additionally, the bio-psychosocial approach to the study of Tx individuals is again highlighted because the reasons any one individual identifies as Tx are likely numerous (Erickson-Schroth, 2013). While causes for gender incongruence may depend on a milieu of origins, we are left to acknowledge current theories involve regions of the RA, specifically the limbic system.

While many similar structures have been implicated in Tx and non-heterosexual subjects, most non-heterosexuals are not Tx, and some Tx individuals are heterosexual. Noncisgender individuals are less likely to reproduce as much as the cisgender population (Swaab \& Garcia, 2009) and therefore tend more toward reproductive isolation despite their permanent place in evolution (Rice, Friberg, \& Gavrilets, 2012).

The pattern for the causes of gender incongruence suggests they may be any or many, leading to many phenotypes. For example, WM studies suggest that MtFs do not show a simple feminization of their brains; instead, they present a complex picture of feminized and incompletely masculinized structures (Guillamon, Junque, \& Gómez-Gil, 2016). While causes may depend on this milieu of origins, we are left to acknowledge current cisgender and Tx theories involving regions of the RA, specifically the limbic system. These distinctions provide further support for the probability that the RA's physiological regions form a neural location for gender, physically and temporally separate to body sex, at least in part.

\subsection{Trans canalization.}

In this paper, canalized psycho-neuroanatomy in the majority cisgender population refers to sex differences in sections of the RA that are moderately focused toward opposite endpoints of a spectrum. Under this theory, it follows that sections of the RA in trans individuals are also majority canalized towards female and male endpoints. Identity labels are umbrella terms (Davidson, 2007), and given the cisgendered variation within and between individuals and groups, it also follows that there is individual variation within the trans community. 


\section{Persisters and Desisters.}

While debates about the validity of labeling children as persisters and desisters have been prominent (Temple-Newhook et al., 2018; Zucker, 2018), this article has asked if there is no internal locus for gender identity, then what is it very young and persisting adult $\mathrm{Tx}$ individuals feel is inconsistent with their bodily sex?

Permanent morphological changes in the CNS may occur due to exposure to steroid hormones at approximately the time of birth. Overt genital anatomy "will radically shape the child's social environment" (Zuloaga et al., 2009, p. 352), or earlier if the sex of a child is known antenatally.

Most children express their sense of gender and correctly label others by age two or three (Ahmed et al., 2004; Leinbach \& Fagot, 1986). After children learn that they are girls or boys, they engage in activities they identify as appropriate for their sex (Hines, 2020). Prepuberty (ages 3-12) is arguably a time when most gender opposite children, with or without any dysphoria, have not necessarily had sufficient time to comprehend their dissonance nor any competing script to how they feel and behave, and especially in the very young. Gender non-conformity has been shown as early as age two (Vance, Ehrensaft, \& Rosenthal, 2014).

"Pubertal hormones likely contribute to the dramatic changes in behavior and brain structure in human adolescents." Brain maturity during adolescence as measured in amygdala and hippocampal volumes, contributes to emotional regulation differences in girls and boys (Frere et al., 2020). The concurrent "emergence of sex differences in mood and anxiety disorders during adolescence may relate to sex differences in brain development or sex differences in pubertal hormones" (Marsh et al., 2008, p. 7).

On the other hand, children experiencing GD pre- and post-puberty (persisters) do not appear to be affected by puberty's usual sex hormone activations (Guillamon, Junque, \& Gómez-Gil, 2016).

Many early-onset Tx individuals, anywhere in the order of 70-98\% (Steensma, Biemond, de Boer, \& Cohen-Kettenis, 2011), may desist and return to their cisgender life both due to the resolution of difficulties other than sexual dimorphism and sex hormone changes in puberty (Gliske, 2019). Others claim, "It would be surprising if the large orientation differences in childhood gender nonconformity disappeared without a trace by adulthood" (Bailey et al., 2016, p. 58). For example, childhood occupational and recreational interests appear to linger into adulthood (Bailey et al., 2016).

In the less susceptible pubescent children who 'desist,' the activational effects of adolescent sex hormones and environment might play a significant role in their mindset (Guillamon, Junque, \& Gómez-Gil, 2016). Synaptic plasticity (Tozzi et al., 2019; Gräff et al., 2011) may also account for how changes in sex hormones in aging contribute to late-onset dysphoria.

Crucially, the percentage of 'desisters' does not number 100\%. Furthermore, the notional merging into sex/gender of otherwise distinct sex and gender, and the claims that gender is a 
social construct, seem to ignore both the very young pre-pubescent Tx children who persist post-puberty as well as individuals who experience, re-experience or relive a gender opposite to their bodily sex later in life.

This current paper has focused on the specific cognitions driven by reproductive networks in the RA as the foundation of gender identity. Our observation is that the causes of gender incongruence are similarly the source of congruent cognitive differences in the cisgender population, namely those related to cognitions linked to reproductive behaviors, highlighting the similar biological origins of gender identity.

\section{DISCUSSION}

It is challenging to "unravel the function of neural circuitry in general... This makes it tricky to link relatively consistent sex differences in brain structure to more fickle sex differences in brain function" (de Vries \& Södersten, 2009. p. 589). When differences are contextdependent across domains, it becomes even more complicated unravelling sex and gender discussions (Del Giudice et al., 2012), and more so when it may not be acted upon until adolescent hormones kick in (Jones \& Lopez, 2014).

Methodological questions abound. Should researchers adjust for raw neuroanatomical volumes as many have done? Which morphological covariate, such as weight, height, head circumference, should be used to adjust for the proposed variations under investigation initially? What statistical methods will be used to elicit results? Last but not least, what about sample size? With a large enough sample, any difference can be regarded as statistically significant. What more, statistical significance does not necessarily equal scientific relevance, and $p$ values in statistics do not measure the importance of a result. A 'small' effect size does not equal a trivial effect (Sanchis-Segura et al., 2019).

As we and others have mentioned, biology and culture work hand in hand, and it is very difficult to impossible to separate the influences of one from the other (Joel, GarciaFalgueras, \& Swaab, 2020; Fine, Joel \& Rippon, 2019). Regardless, some authors have not made what we consider a meaningful distinction between general cognitive behaviors and those relative to reproduction, choosing instead to consider behaviors related to 'reproduction' as physical and nothing more, seemingly bypassing limbic system function relative to reproduction. "From flies to mice and rats, sex behavior is controlled to match the reproductive capacity of each individual and the availability of resources" (Lenschow \& Lima, 2020, p. 164).

In this review, we have separated general behavior from cognitive behavior relevant to reproduction and maintained the RA, specifically the limbic system, as the center of gender identity. This separation allows us to see how pubescent children who consistently, persistently, and insistently (Olson \& Gülgöz, 2018) maintain a gender opposite to that assigned at birth, and whose later reproductive behavior is not always conventional for their sex, arguably makes the notion of gender as a singular social category of sex/gender insufficient. 
Accepting sexuality as the global term concerning reproduction presented earlier and the differences in courtship, aggression, empathy, and care of offspring as essential to reproduction, the significance of the RA, and especially the limbic system, to gender identity, becomes more evident. While there will be some overlap in behaviors related to reproduction, and gender is not categorical, they are sufficiently polarized that average differences remain significant and relevant (McCarthy et al., 2017).

Borrowing from McCarthy et al. (2017), we can say a handful of sex differences in the CNS can be linked to differences in sexual (physical) behavior. Of most other (cognitive) sex differences, we can ask would dimorphic differences give males and females any advantage in terms of function. Humanity endures through a cycle of reproduction and survival, and the claim that human behavior is, therefore, dependent on associated physical and cognitive behaviors is worthy of examination. Such an examination may also answer the hypothetical question of why we would have a gender at all.

This article presented the RA as the broad location of gender with the possibility of more localization in the amygdala and putamen. Despite the mosaic of other cognitive behaviors, gender identity has been presented as differential and tethered to behaviors, specializations, and responsiveness relevant to the RA, hardwired into the subsystems of the cortex and limbic system, and separate to higher-order executive functions regulated by gray and white matter.

Fronto-parietal connectivity theories of identity suggest connectivity between inter- and intra-connectivity networks is different in Tx males than in cisgender males, i.e., there is an altered connectivity phenotype or a disconnectivity in parietal regions.

Differences in gender variants were not restricted to a single network but rather to the interaction of several networks... The interaction between neurological networks is reportedly a foundation to building a gendered self (Uribe et al., 2020, pp, 11, 1).

The location of gender presented more broadly herein is in line with body perception network models. Body perception models present their fixed neurophysiological signature related to interconnected networks in the frontoparietal cortex, amygdala, hypothalamus, and putamen i.e., in the whole RA. The behaviors associated with the RA networks are presented as moderately focused or canalized towards male and female endpoints. This awareness is present in both cis and Tx gendered individuals and is otherwise known as body perception.

\section{CONCLUSION}

This project evolved out of a desire to answer the question; how is it that dimorphic bodily sex creates two distinctly different reproductive systems yet allows for a human mosaic of cognitions that are surprisingly similar yet flexible (Fine, 2020)? To begin our research, we turned the question upside down and asked; considering that we are not a heteromorphic species and only females endure the physicality of childbirth, and males do not, why wouldn't there be differences in innate cognitions relative to the differences in the reproductive burden which are adaptive? This paper does not propose $\mathrm{T}$ or estrogen 
hardwire gender identity per se; rather, reproductive hormones hardwire the inclination toward male or female cognitions relative to reproduction, which contribute to gender identity.

To this end, this review carried out four primary goals:

(1) split the behavioral domain of the general cognitive mosaic of functions from those cognitions explicitly related to reproduction.

(2) examined the possible location of biological origins and for those cognitions and whether they are dimorphic.

(3) presented dimorphic neural regions and their associated behaviors as the source of gender.

(4) examined the same regions in the trans (Tx) community for support or otherwise for the biological source of gender.

Under the assumption that there are life-long differences between the sexes, our goal was to reason backward to see if and what behavioral differences mattered to reproduction alone, i.e., species survival.

Then by asking what it is those very young Tx children identify as opposing their sex assigned at birth, we examined similar regions to the cisgender community.

If evolution has selected sex-specific organization relevant to reproductive fitness, then neural circuitry will also be a function of sex (Sisk, 2016). However, when it comes to emotions, even Darwin was puzzled. Emotional differences have still to be fully understood from an evolutionary perspective; nonetheless, according to the theory of phenotypic variation for expressed emotion, sex-typical emotive behaviors co-evolved to "regulate interpersonal dynamics that enhance social fitness" (Vigil, 2009, p. 376).

"The adaptive significance of affective responses (e.g., emotions, dispositions, moods) lies in their expression and that affect behaviors function to systematically motivate other people to respond to the signaller in ways that enhance the signaller's fitness" (Vigil, 2009, p. 376). The differential in reproductive burden indeed necessitates differences in effective responses that are characterized by gender differences.

The self-domestication hypothesis claims social skills evolved when natural selection favored increased self-control and group pro-sociality over aggression in late human evolution (Green \& Spikins, 2020; Hare, 2017). Accordingly, we can add that effective responses such as empathy and contemporary aggression (a competitive spirit in combination with the defence of resources, self-defence, and defence of significant others), as presented herein, are adaptive behaviors in that they aid the survival of offspring. These gender differences become apparent in the biology of the reproductive axis. Thus, the essence of gender is our subconscious awareness of our reproductive Id or archetype. 
'Essence' is a rather vague descriptor in neuroscience, however, when we adapt McFadden (2021), it isn't so much how DNA or all the information in millions of cerebral neurons come together to create conscious perception of thoughts, gender, or anything else, rather, information encoded by the neurons is unified within a single brain electromagnetic (EM) field. "Every time a neuron fires, along with the matter-based signal that travels down its wire-like nerve fibre, it also projects a tiny electromagnetic pulse into the surrounding space...". These EM pulses flow into each other to generate a kind of pool of energy that's called an electromagnetic field generated by their firing. Information encoded in billions of distributed neurons is unified in our (EM field-based) conscious mind (see McFadden, 2021).

All factors considered, we know that sex-related brain structures in the RA are at least partly distinguished pre- and post-natally, so EM biology drives this part of one's self-concept (recognized in Freudian psychoanalysis as the "Id"), while the other is socially constructed (recognized in Freudian terms as the 'Superego'). In Jungian psychoanalysis, the "archetype" is where latent instinctual energies await development and expression.

The framework of evidence for sex vs. gender in the reproductive axis and the effects of incongruence in Tx healthy subjects has not been presented previously. The evidence reviewed in the cis and Tx communities points to the RA's key role in coding for gender identity.

This differential organization of the fetus and its brain must be managed or directed one way or another, or as Purves implied - bodily processes must be linked to neural differentiation (Purves, 1989). Because of temporal linking and the consecutive organization of body and brain, the two processes can be influenced independently, resulting in their miss-alignment or incongruence (Bao \& Swaab, 2011; Savic, Garcia-Falgueras, \& Swaab, 2010).

Currently as research stands, there is no biological marker for gender (Byne et al., 2018). With a biology for gender, the ability to study it further and search for a biological marker of gender could lie hand in hand with its neurological location. Variation in the linkage of sex and gender implied by Purves (1989) could further provide a unified explanation for conventional and unconventional human diversity alike. Variation in this linkage could be significant to a causal explanation for gender diversity within linked spectra.

A physiological location for gender distinct from sex could help advance the apolitical understanding of unconventional or incongruent gender identities. As mentioned, sexual dimorphisms may instead be located anywhere along a spectrum. It is clear, for example, that spectra distribute sexual orientation (Savin-Williams, 2014) from attraction to the opposite sex, the same sex, both, or none. Sex differentiation is "typically associated with a spectrum of external genital development" (Lee et al., 2016, p, 164), accounting for disorders of sex development (García-Acero et al., 2020) or the reported 2\% frequency of intersex individuals in humans (Blackless et al., 2000), while others classify intersex as a phenotype, not a genotype (Wizemann \& Pardue, 2001). The prevalence of GID across different cultures has been reported as anywhere between $0.003 \%$ to $1.3 \%$ (Byne, et al., 2018). Although Montanez (2017) presented a striking visual representation of the convoluted pathways within the spectra of disorders of sex development (DSD), gender per 
$s e$ is not represented. This is unsurprising as there is currently no agreed upon biological representation of gender. Borrowing from Meyer-Bahlburg (2019), while it may be recognized XX / XY genetic binaries canalize differentiated taxons, the existence of intersex bodies, although rare, testifies to the overlapping of canalized bodily sex (García-Acero et al., 2020; Swaab \& Bao, 2016; Ainsworth, 2015). O'Hanlan, Gordon, and Sullivan (2018) present an example of over 450 quadrillion possibilities of dimorphism.

Combined with our unique human consciousness and self-awareness, essential cognitive and emotional differences described herein credibly make for our perpetual sense of gender, from which men and women adopt a gender role identity to express gender via individual gendered displays in their social world (West \& Zimmerman, 2009).

In conclusion, we propose that gender identity is the innate sense of ourselves as the EM arising out of the interlinked networks of the reproductive axis. This network could be represented by the pseudo-equation: gender identity $=$ EMcortex + EMprefrontal cortex + EMpituitary + EMlimbic system (hippocampus, amygdala, hypothalamus). This "equation" does not represent how the various elements are not necessarily additive and are not necessarily equally weighted. It does represent the multifaceted components involved in gender identity as well as in gender incongruence. Furthermore, considering neural interconnectivity, it would be difficult to argue differences in aggression and empathy do not filter into other neural networks adding to gender's canalization. Gender identity is therefore presented as innate and aligned with our future reproductive roles as mothers and fathers.

Because of the temporal nature of this linking and the consecutive organization of body and brain, the two processes can be influenced independently, "Any theory that brings some clarity into this discussion could be appealing and even better if it differentiated sexual motivation from sexual orientation (Imhoff et al., 2017) and sex from gender from sexuality from gender roles" (Author 1 \& Author 2, (a) in preparation).

\subsection{Postscript -The end of Gender?}

"At the beginning of the 21st century, [however], posthumanist and transhumanist discourses about using technologies to intentionally transcend the limitations of the human body began to address the transcending of gender."

(Dvorsky \& Hughes, 2008, p. 7).

McCarthy and Arnold (2011) proposed X and Y genes are the factors at the root of all differences in the human phenotype, yet, some predict 'gender' as we know it may cease to exist in the distant future. Indeed the concept of "gender isn't what it used to be" (see Thurer, 2005). That premise is based initially on social construction theory, with gender regarded as forming solely under the influence of parenting and society.

Under this radical social construction of gender, it is indeed feasible differences in gendered behavior could be erased (see Author $1 \&$ Author 2, 2004). However, the social 
construction of gender does not explain the innate differences between males and females presented herein.

Evolution, as understood by Darwin, evolutionary psychology, and human behavioral ecology (where genes and culture interact slowly over millennia), could be outpaced by technology, whereby alteration in the ecology of gender may become feasible. The role of reproductive hormones in uterine development also spawned the possibility of psychopharmacology that may increase control over gender emotions and cognitions, for example, suppressing the male propensity for violence (Dvorsky \& Hughes, 2008).

Considering the relationship between parenting and technology has always existed, and the exponential rate of technological advance we are now experiencing (Kushnick, 2018), along with our Lamarckian ability to adapt phenotypically, microbiologists have discovered ways to interfere with the chromosomes of plants, animals, and humans under the aegis of genetic engineering.

Postgender technologies may put an end to static biological and sexual selfidentification, allowing individuals to decide for themselves which biological and psychological gender traits they wish to keep or reject.

(Dvorsky \& Hughes, 2008).

Molecular biologist Elizabeth Finkel has asked what have we learned from all this (Finkel, 2012)? Alongside the momentum in neurotechnology, biotechnology, and reproductive technologies, we may be moving into a post-Darwinian, post-human era (Killeen, 2019; Dvorsky \& Hughes, 2008) and on to the slow erosion of sex and gender as binaries.

Though that does seem a long bow to draw, Dvorsky and Hughes $(2008$, p. 7) assert that "Today's transgender movement is a roiling, radical critique of the limits of gender roles, with folks living in totally new categories, such as non-op transsexual, TG butch, femme queen, cross-dresser, third gender, drag king or queen and transboi." These authors present the focus on a landscape of gender diversity that is somewhat more at the level of ideology, psychology, and culture that lack praxis in the real world.

Feminist and Trans-Exclusionary Radical Feminist (TERF) de-gendering theories (Lu, 2020; Lorber, 2000) "destabilize the fixed and biological root of sexual dimorphism" (Nicholas, 2012, p. 1). Feminist degendering wishes to challenge "simplistic divisions of nature/culture and sex/gender" to eradicate gender differences (Nicholas, 2012, p. 2). Feminists wish to explain away differences based on cultural conditioning (Feldman \& Lindquist, 2021).

Neo-androgynists agree, nevertheless, they highlight the split between socialized and innate behaviour and do not promote de-gendering the sexes or interfering with individual identity (Author $1 \&$ Author 2, (b) in preparation).

In parallel, some have alerted the world to another problem. Sperm counts have been declined significantly between 1973 and 2011 in men from North America, Europe, and Australia, with no signs of levelling off. Possible causes have been attributed to environmental and lifestyle issues, including endocrine disrupting chemicals, or maternal smoking (Levine et al., 2017). 
The call to free ourselves from the categories of gender presents a problem. Considering the broader acceptance of gender as a spectrum, there can be no end to identity terminology, as foreshadowed above.

In contrast to the debates between radical social constructionism and radical gender essentialism, we see a resolution in the balanced bio-psycho-social or psychological constructionism models. We can speculate via the notion of canalization as presented herein; there is sufficient overlap in the human phenotype to restrict the free-for-all labelling to a few polarized labels, such as the LGBTQI (lesbian, gay, bisexual, trans, queer, intersex) currently in use (Author $1 \&$ Author 2, (a) in preparation).

This paper maintains the inseparability of spectrums for sex from gender, and reduces difference to reproductive behaviors rather than reifying difference, leaving the remainder of behavior available in sufficient quantities to both sexes without any imposed hierarchy or exclusion.

In response to the clarion feminist cry that dyadic gender roles and sexual dimorphisms are to the detriment of individuals, we maintain reproductive gender as innate. We have always seen this cry more as a mistaken attempt to adopt an androgynous personality, no matter how one identifies (Author 1 \& Author 2, (b), in preparation).

\section{Declarations}

This research did not receive any specific grant from funding agencies in the public, commercial, or not-for-profit sectors.

Conflict of interest: The authors declare they have no conflicts of interest.

Human and Animal Rights: This article does not contain any studies with human participants or animals performed by the author.

\section{CRediT author statements.}

Author 1: Conceptualization; Project administration; Resources; Software; Writing - original draft \& editing; Writing - review \& editing.

Author 2: Project administration; Writing - review \& editing. 


\section{References}

AACB (2020). Australian Association for Clinical Biochemistry and Laboratory Medicine. Retrieved from https://www.labtestsonline.org.au. Visited August 16, 2020.

Acevedo-Rodriguez, A., Kauffman, A., Cherrington, B., Borges, C., Roepke, T., \& Laconi, M. (2018). Emerging insights into hypothalamic-pituitary-gonadal axis regulation and interaction with stress signalling. Journal of neuroendocrinology, 30(10), e12590.

Ahmed, S., Morrison, S., \& Hughes, I. (2004). Intersex and gender assignment; the third way? Archives of Disease in Childhood, 89, 847-850.

Ainsworth, C. (2015). Sex redefined. Nature, 518(7539), 288.

Alexander, G. (2003). An evolutionary perspective of sex-typed toy preferences: Pink, blue, and the brain. Archives of sexual behavior, 32(1), 7-14.

Ali, F., Amorim, I.., \& Chamorro-Premuzic, T. (2009). Empathy deficits and trait emotional intelligence in psychopathy and Machiavellianism. Personality and Individual Differences, 47(7), 758-762.

Alzahrani, A., Ahmad, A., Alhazmi, T., \& Ahmad, L. (2019). An Isolated Hypogonadotropic Hypogonadism due to a L102P Inactivating Mutation of KISS1R/GPR54 in a Large Family. Case Reports in Pediatrics, 2019.

Arnold, A. (2017). A general theory of sexual differentiation. Journal of neuroscience research, 95(1-2), 291-300.

Arnold, A., Xu, J., Grisham, W., Chen, X., Kim, Y., \& Itoh, Y. (2004). Minireview: Sex chromosomes and brain sexual differentiation. Endocrinology, 145(3), 1057-1062.

Atzil, S., Hendler, T., \& Feldman, R. (2011). Specifying the neurobiological basis of human attachment: brain, hormones, and behavior in synchronous and intrusive mothers.

Neuropsychopharmacology, 36(13), 2603-2615

Author 1., \& Author 2. (a) (in preparation), Spectra of Identity: Shades of pink and blue.

Author 1., \& Author 2. (2004).

Author 1., \& Author 2. (b) (in preparation), Androgyny - shaken, not stirred: De-Gendering psychological androgyny theory.

Auger, A., \& McCarthy, M. (2017). Epigenetic Contribution to Sex Differences in Hormones, Brain and Behavior (Third edition). 
Auyeung, B., Wheelwright, S., Allison, C., Atkinson, M., Samarawickrema, N., \& BaronCohen, S. (2009). The children's empathy quotient and systemizing quotient: Sex differences in typical development and in autism spectrum conditions. Journal of autism and developmental disorders, 39(11), 1509-1521.

Bailey, J., Vasey, P., Diamond, L., Breedlove, S., Vilain, E., \& Epprecht, M. (2016). Sexual orientation, controversy, and science. Psychological Science in the Public Interest, 17(2), 45-101.

Baldinger-Melich, P., Urquijo Castro, M., Seiger, R., Ruef, A., Dwyer, D., Kranz, G., et al. (2019). Sex matters: a multivariate pattern analysis of sex-and gender-related neuroanatomical differences in cis-and transgender individuals using structural magnetic resonance imaging. Cerebral Cortex, 30(3), 1345-1356.

Bao, A., \& Swaab, D. (2011). Sexual differentiation of the human brain: Relation to gender identity, sexual orientation and neuropsychiatric disorders. Frontiers in Neuroendocrinology, 32, 214-226.

Baron-Cohen, S., O’Riordan, M., Jones, R., Stone, V., \& Plaisted, K. (1999). A new test of social sensitivity: Detection of faux pas in normal children and children with Asperger syndrome. Journal of Autism and Developmental Disorders, 29(5), 407-418.

Bartky, S. (1999). Femininity and domination. In C. C. Gould (Ed.), Key concepts in theory: Gender. New York: Humanity Books.

Batrinos, M. (2012). Testosterone and aggressive behavior in man. International journal of endocrinology and metabolism, 10(3), 563.

Batson, C., Duncan, B., Ackerman, P., Buckley, T., \& Birch, K. (1981). Is empathic emotion a source of altruistic motivation?. Journal of personality and Social Psychology, 40(2), 290.

Beking, T., Burke, S. Geuze, R., Staphorsius, A., Bakker, J., Groothuis, A., et al. (2020). Testosterone effects on functional amygdala lateralization: A study in adolescent transgender boys and cisgender boys and girls. Psychoneuroendocrinology, 111, 104461.

Berenbaum, S., \& Beltz, A. (2016). How early hormones shape gender development. Current opinion in behavioral sciences, 7, 53-60.

Björkqvist, K. (1994). Sex differences in physical, verbal, and indirect aggression: A review of recent research. Sex roles, 30(3), 177-188.

Blackless, M., Charuvastra, A., Derryck, A., Fausto-Sterling, A., Lauzanne, K. \& Lee, E. (2000). How sexually dimorphic are we? Review and synthesis. American Journal of Human Biology: The Official Journal of the Human Biology Association, 12(2), pp.151-166.

Blair, J., McGee, H., Bhatta, S., Palm, R., \& Casadesus, G. (2015). Hypothalamic-pituitarygonadal axis involvement in learning and memory and Alzheimer's disease: more than “just" estrogen. Frontiers in Endocrinology, 6, 45.

Broidy, L., Cauffman, E., Espelage, D., Mazerolle, P., \& Piquero, A. (2003). Sex differences in empathy and its relation to juvenile offending. Violence and victims, 18(5), 503-516.

Bonelli, R., \& Cummings, J. (2007). Frontal-subcortical circuitry and behavior. Dialogues in clinical neuroscience, 9(2), 141. 
Braga, J., Samir, C., Risser, L., Dumoncel, J., Descouens, D., Thackeray, J., et al. (2019). Cochlear shape reveals that the human organ of hearing is sex-typed from birth. Scientific reports, 9(1), 1-9.

Burke, S., Manzouri, A., \& Savic, I. (2017). Structural connections in the brain in relation to gender identity and sexual orientation. Scientific reports, 7(1), 1-12.

Burke, S., Van Heesewijk, J., Menks, W., Klink, D. T., Kreukels, B., Cohen-Kettenis, P., et al. (2020). Postnatal effects of sex hormones on click-evoked otoacoustic emissions: A study of adolescents with gender dysphoria. Archives of Sexual Behavior, 49(2), 455-465.

Buss, D. (1995). Evolutionary Psychology: A new paradigm for psychological sciences. Psychological Enquiry, 6, 1-30.

Buss, D. (2009). The role of emotions in adaptations for exploitation. Behavioral and Brain Sciences, 32(5), 391.

Butler, J. (1990). Gender trouble. Feminism and the Subversion of Identity. New York, NY. Routledge.

Byne, W., Karasic, D., Coleman, E., Eyler, A., Kidd, J., Meyer-Bahlburg, H., ... \& Pula, J. (2018). Gender dysphoria in adults: an overview and primer for psychiatrists. Transgender Health, 3(1), 57-A3.

Cahill, L., Uncapher, M., Kilpatrick, L., Alkire, M., Turner, J. (2004). Sex-related hemispheric lateralization of amygdala function in emotionally influenced memory: an FMRI investigation. Learn. Mem. 11 (3), 261-266.

Calisi, R., Austin, S., Lang, A., \& MacManes, M. D. (2018). Sex-biased transcriptomic response of the reproductive axis to stress. Hormones and behavior, 100, 56-68.

Card, N., Stucky, B., Sawalani, G., \& Little, T. (2008). Direct and indirect aggression during childhood and adolescence: A meta-analytic review of gender differences, intercorrelations, and relations to maladjustment. Child development, 79(5), 1185-1229.

Carothers, B., \& Reiss, H. (2013). Men and women are from earth: Examining the latent structure of gender. Journal of Personality \& Social Psychology, 104, 2, 385-407. doi: 10 1037/a0030437

Carrier, D., Schilling, N., \& Anders, C. (2015). Muscle activation during maximal effort tasks: evidence of the selective forces that shaped the musculoskeletal system of humans. Biology open, 4(12), 1635-1642.

Carroll, C. (2021). Female excellence in rock climbing likely has an evolutionary origin. Current Research in Physiology, https://doi.org/10.1016/j.crphys.2021.01.004.

Castillo-Fernandez, J., Spector, T., \& Bell, J. (2014). Epigenetics of discordant monozygotic twins: implications for disease. Genome medicine, 6(7), 60.

Champagne, F., \& Curley, J. (2016). Plasticity of the maternal brain across the lifespan. New directions for child and adolescent development, 2016(153), 9-21.

Chaplin, T. (2015). Gender and emotion expression: A developmental contextual perspective. Emotion Review, 7(1), 14-21. 
Chapman, E., Baron-Cohen, S., Auyeung, B., Knickmeyer, R., Taylor, K., \& Hackett, G. (2006). Fetal testosterone and empathy: evidence from the empathy quotient (EQ) and the "reading the mind in the eyes" test. Social Neuroscience, 1(2), 135-148.

Chen, P., Hu, R., Wu, Y., Pan, L., Huang, S., Micevych, P., \& Hong, W. (2019). Sexually dimorphic control of parenting behavior by the medial amygdala. Cell, 176(5), 1206-1221.

Chittka, L., \& Niven, J. (2009). Are bigger brains better?. Current biology, 19(21), R995R1008.

Chodorow, N. (1999). The reproduction of mothering: Psychoanalysis and the sociology of gender. University of California Press.

Christov-Moore, L., Simpson, E., Coudé, G., Grigaityte, K., Iacoboni, M., \& Ferrari, P. (2014). Empathy: gender effects in brain and behavior. Neuroscience \& Biobehavioral Reviews, 46, 604-627.

Chung, W. De Vries, G., \& Swaab, D. (2002). Sexual differentiation of the bed nucleus of the stria terminalis in humans may extend into adulthood. Journal of Neuroscience, 22(3), 1027-1033.

Cohen-Bendahan, C., Buitelaar, J., Van Goozen, S., Orlebeke, J., \& Cohen-Kettenis, P. (2005). Is there an effect of prenatal testosterone on aggression and other behavioral traits? A study comparing same-sex and opposite-sex twin girls. Hormones and Behavior, 47(2), 230-237.

Cohen, J. (1988). Statistical power analysis for the behavioral sciences (2nd ed.). Hillsdale, NJ: Erlbaum.

Connellan, J., Baron-Cohen, S., Wheelwright, S., Batki, A., \& Ahluwalia, J. (2000). Sex differences in human neonatal social perception. Infant behavior and Development, 23(1), 113-118.

Couse, J., Yates, M., Walker, V., \& Korach, K. S. (2003). Characterization of the hypothalamic-pituitary-gonadal axis in estrogen receptor (ER) null mice reveals hypergonadism and endocrine sex reversal in females lacking ER $\alpha$ but not ER $\beta$. Molecular Endocrinology, 17(6), 1039-1053.

Crestani, C., Alves, F., Gomes, F., Resstel, L., Correa, F., \& Herman, J. (2013). Mechanisms in the bed nucleus of the stria terminalis involved in control of autonomic and neuroendocrine functions: a review. Current neuropharmacology, 11(2), 141-159.

Cromwell, H., Abe, N., Barrett, K, Caldwell-Harris, C., Gendolla, G., Koncz, R., \& Sachdev, P. S. (2020). Mapping the interconnected neural systems underlying motivation and emotion: A key step toward understanding the human affectome. Neuroscience \& Biobehavioral Reviews, 113, 204-226.

Davidson, L., Vandongen, R., Rouse, I., Beilin, L., \& Tunney, A. (1984). Sex-related differences in resting and stimulated plasma noradrenaline and adrenaline. Clinical science, 67(3), 347-352.

De Vries, A., Noens, I., Cohen-Kettenis, P., van Berckelaer-Onnes, I., \& Doreleijers, T. (2010). Autism spectrum disorders in gender dysphoric children and adolescents. Journal of autism and developmental disorders, 40(8), 930-936. 
De Vries, G., \& Södersten, P. (2009). Sex differences in the brain: the relation between structure and function. Hormones and behavior, 55(5), 589-596.

Decety, J., \& Lamm, C. (2006). Human empathy through the lens of social neuroscience. TheScientificWorldJOURNAL, 6, 1146-1163.

van der Dennen, J. (2005). Introduction to The Nature of the Sexes. In The Nature of the Sexes: The Sociobiology of Sex Differences and the 'Battle of the Sexes'.

Del Giudice, M., Booth, T., \& Irwing, P. (2012). The distance between Mars and Venus: Measuring global sex differences in personality. PloS one, 7(1).

Denley, M., Gatford, N., Sellers, K., \& Srivastava, D. (2018). Estradiol and the development of the cerebral cortex: an unexpected role?. Frontiers in neuroscience, 12, 245.

Doidge, N. (2008). The brain that changes itself. Melbourne: Scribe.

Dvorsky, G., \& Hughes, J. (2008). Postgenderism: Beyond the gender binary. Institute for Ethics and Emerging Technologies, 20, 44-57.

Eagly, A., \& Wood, W. (2013). The nature-nurture debates: 25 years of challenges in understanding the psychology of gender. Perspectives on Psychological Science, 8(3), 340357.

Eliot, L., Ahmed, A., Khan, H., Patel, J. (2021). Dump the "dimorphism": Comprehensive synthesis of human brain studies reveals few male-female differences beyond size, Neuroscience \& Biobehavioral Reviews, in press. doi.org/10.1016/j.neubiorev.2021.02.026. Eme, R. (1992). Selective females affliction in the developmental disorders of childhood: A literature review. Journal of Clinical Child Psychology, 21(4), 354-364.

Erickson-Schroth, L. (2013). Update on the biology of transgender identity. Journal of Gay \& Lesbian Mental Health, 17(2), 150-174.

Erickson, K., Voss, M., Prakash, R., Basak, C., Szabo, A., Chaddock, L., ... \& Kramer, A. (2011). Exercise training increases size of hippocampus and improves memory. Proceedings of the National Academy of Sciences, 108(7), 3017-3022.

Fan, L., Li, H., Zhuo, J., Zhang, Y., Wang, J., Chen, L., et al. (2016). The human brainnetome atlas: a new brain atlas based on connectional architecture. Cerebral cortex, 26(8), 3508-3526.

Fang, Y., Yamaguchi, T., Song, S., Tritsch, N., \& Lin, D. (2018). A hypothalamic midbrain pathway essential for driving maternal behaviors. Neuron, 98(1), 192-207.

Fathalla, M. (2015). Women and the burden of human reproduction: an evolutionary perspective. Journal of Reproductive Health and Medicine, 1(2), 103-105.

Fausto-Sterling, A. (2018). Why sex is not binary. The New York Times, 25.

Feldman, M., \& Lindquist, K. (2021) What makes a woman's body? Retrieved from https://aeon.co/essays/womens-bodies-emerge-on-the-shoreline-between-biology-andculture?utm_source=Aeon Visited January 23, 2021. 
Fernández, R., Guillamon, A., Cortés-Cortés, J., Gómez-Gil, E., Jácome, A., Esteva, I., et al. (2018). Molecular basis of Gender Dysphoria: androgen and estrogen receptor interaction. Psychoneuroendocrinology, 98, 161-167.

Fernández, R., Delgado-Zayas, E., Ramírez, K., Cortés-Cortés, J., Gómez-Gil, E., Esteva, I., ... \& Pásaro, E. (2020). Analysis of four polymorphisms located at the promoter of the estrogen receptor Alpha ESR1 gene in a population with gender incongruence. Sexual medicine, 8(3), 490-500.

Feusner, J., Lidström, A., Moody, T., Dhejne, C., Bookheimer, S., \& Savic, I. (2017). Intrinsic network connectivity and own body perception in gender dysphoria. Brain imaging and behavior, 11(4), 964-976.

Fiani, C. (2018). Beyond the Binary: Gender Identity and Mental Health Among Transgender and Gender Non-Conforming Adults. CUNY Academic Works.

Flasbeck, V., Enzi, B., \& Brüne, M. (2019). Enhanced processing of painful emotions in patients with borderline personality disorder: a functional magnetic resonance imaging study. Frontiers in psychiatry, 10, 357.

Fine, C. (2017). Testosterone rex: unmaking the myths of our gendered minds. Icon Books.

Fine, C. (2020). Sexual Dinosaurs. Retrieved from https://aeon.co/essays/trumped-upcharges-of-feminist-bias-are-bad-for-science. Visited August 6, 2020.

Fine, C., Joel, D., \& Rippon, G. (2019). Eight things you need to know about sex, gender, brains, and behavior: A guide for academics, journalists, parents, gender diversity advocates, social justice warriors, tweeters, Facebookers, and everyone else not otherwise specified. Scholar \& Feminist Online, 15.

Finkel, E. (2012). The Genome Generation. Melbourne Univ. Publishing.

Fisher, A., Ristori, J., Castellini, G., Cocchetti, C., Cassioli, E., Orsolini, S., et al. (2020). Neural Correlates of Gender Face Perception in Transgender People. Journal of Clinical Medicine, 9(6), 1731.

Francis, B. (2012). Gender monoglossia, gender heteroglossia: the potential of Bakhtin's work for re-conceptualising gender. Journal of Gender Studies, 21(1), 1-15.

Frere, P., Vetter, N.., Artiges, E., Filippi, I., Miranda, R., Vulser, H., Paillère-Martinot, M., Ziesch, V., Conrod, P., Cattrell, A., \& Walter, H.. (2020). Sex effects on structural maturation of the limbic system and outcomes on emotional regulation during adolescence. NeuroImage, 210, 116441.

Freud, S. (1966). Project for a scientific psychology (1950 [1895]). In The Standard Edition of the Complete Psychological Works of Sigmund Freud, I (1886-1899): Pre-PsychoAnalytic Publications and Unpublished Drafts , 281-391.

Fuster, J. (2009). Prefrontal Cortex. In Larry Squire (Ed.), Encyclopedia of Neuroscience (pp. 905-908). Academic Press.

García-Acero, M., Moreno-Niño, O., Suárez-Obando, F., Molina, M., Manotas, M., Prieto, J., et al. (2020). Disorders of sex development: Genetic characterization of a patient cohort. Molecular Medicine Reports, 21(1), 97-106. 
Ghandili M., Munakomi S. (2020). Neuroanatomy. StatPearls Publishing. https://www.ncbi.nlm.nih.gov/books/NBK542170/. Visited August 6, 2020.

Gilligan, C. (1993). In a different voice. Harvard University Press.

Gliske, S. (2019). A new theory of gender dysphoria incorporating the distress, social behavioral, and body-ownership networks. ENeuro, 6(6).

Glover, E., Jovanovic, T., Mercer, K., Kerley, K., Bradley, B., Ressler, K., et al. (2012). Estrogen levels are associated with extinction deficits in women with posttraumatic stress disorder. Biological psychiatry, 72(1), 19-24.

Goldstein, J., Seidman, L., Horton, N., Makris, N., Kennedy, D., Caviness Jr., et al. (2001). Normal sexual dimorphism of the adult human brain assessed by in vivo magnetic resonance imaging. Cerebral cortex, 11(6), 490-497.

Goddings, A., Mills, K., Clasen, L., Giedd, J., Viner, R., \& Blakemore, S. (2014). The influence of puberty on subcortical brain development. Neuroimage, 88, 242-251.

Gooren, L. (2006). The biology of human psychosexual differentiation. Hormones and behavior, 50(4), 589-601.

Gouveia, F., Hamani, C., Fonoff, E., Brentani, H., Alho, E.., De Morais, R., et al. (2019). Amygdala and Hypothalamus: historical overview with focus on aggression. Neurosurgery, 85(1), 11-30.

Grabowska, A. (2017). Sex on the brain: Are gender-dependent structural and functional differences associated with behavior?. Journal of neuroscience research, 95(1-2), 200-212.

Gräff, J., Kim, D., Dobbin, M., \& Tsai, L. (2011). Epigenetic regulation of gene expression in physiological and pathological brain processes. Physiological reviews, 91(2), 603-649.

Green, J., \& Spikins, P. (2020). Not just a virtue: the evolution of self-control. Time and Mind, 1-23.

Greenberg, D, Warrier, V., Allison, C., \& Baron-Cohen, S. (2018). Testing the Empathizing-Systemizing theory of sex differences and the Extreme Male Brain theory of autism in half a million people. Proceedings of the National Academy of Sciences, 115(48), 12152-12157.

Guillamon, A., Junque, C., \& Gómez-Gil, E. (2016). A review of the status of brain structure research in transsexualism. Archives of Sexual Behavior, 45(7), 1615-1648.

Hahn, A., Kranz, G., Küblböck, M., Kaufmann, U., Ganger, S., Hummer, A., et al. (2015). Structural connectivity networks of transgender people. Cerebral Cortex, 25(10), 35273534.

Halpern, D. (2013). Sex differences in cognitive abilities. Psychology press.

Halpern, D., \& Wai, J. (2020). Sex Differences in Intelligence. In R. Sternberg (Ed.), The Cambridge Handbook of Intelligence (Cambridge Handbooks in Psychology, pp. 317-345). Cambridge: Cambridge University Press. doi:10.1017/9781108770422.015

Hare, B. (2017). Survival of the friendliest: Homo sapiens evolved via selection for prosociality. Annual review of psychology, 68, 155-186. 
Heberlein, A., Padon, A., Gillihan, S., Farah, M., \& Fellows, L. (2008). Ventromedial frontal lobe plays a critical role in facial emotion recognition. Journal of cognitive neuroscience, 20(4), 721-733.

Hermans, E. J., Putman, P., \& Van Honk, J. (2006). Testosterone administration reduces empathetic behavior: A facial mimicry study. Psychoneuroendocrinology, 31(7), 859-866.

Hewitt, J., Paul, C., Kasiannan, P., Grover, S., Newman, L., \& Warne, G. (2012). Hormone treatment of gender identity disorder in a cohort of children and adolescents. Medical Journal of Australia, 196(9), 578-581.

Hines, M. (2020). Neuroscience and sex/gender: looking back and forward. Journal of Neuroscience, 40(1), 37-43.

Hines, M. (2017). Gonadal Hormones and Sexual Differentiation of Human Brain and Behavior. Hormones, Brain, and Behavior, 3(5), 247-278, doi.org/10.1016/B978-0-12803592-4.00103-6

Hines, M. (2011). Gender development and the human brain. Annual review of neuroscience, 34, 69-88.

Hinojosa-Laborde, C., Chapa, I., Lange, D., \& Haywood, J. (1999). Gender differences in sympathetic nervous system regulation. Clinical and Experimental Pharmacology and Physiology, 26(2), 122-126.

Hoekzema, E., Schagen, S., Kreukels, B., Veltman, D., Cohen-Kettenis, P., Delemarre-van De Waal, H., et al. (2015). Regional volumes and spatial volumetric distribution of gray matter in the gender dysphoric brain. Psychoneuroendocrinology, 55, 59-71.

Hoffmann, M. (2013). The human frontal lobes and frontal network systems: an evolutionary, clinical, and treatment perspective. ISRN neurology, 2013.

https://academicworks.cuny.edu/gc etds/2815

Huang, H., Xue, R., Zhang, J., Ren, T., Richards, L. J., Yarowsky, P., et al. (2009). Anatomical characterization of human fetal brain development with diffusion tensor magnetic resonance imaging. Journal of Neuroscience, 29(13), 4263-4273.

Huber, R., \& Kravitz, E. (2010). Aggression: towards an integration of gene, brain and behavior. Social behavior: Genes, ecology and evolution, 165-180.

Hyde, J. (2005). The gender similarities hypothesis. American psychologist, 60(6), 581.

Hyde, J. (2014). Gender similarities and differences. Annual review of psychology, 65, 373398.

Hyde, J., Bigler, R., Joel, D., Tate, C., \& Anders, S. (2018). The future of sex and gender in psychology: Five challenges to the gender binary. The American psychologist.

incongruence. International Review of Psychiatry, 28(1), 120-128.

Imhoff, R., Banse, R., \& Schmidt, A. (2017). Toward a theoretical understanding of sexual orientation and sexual motivation. Archives of sexual behavior, 46(1), 29-33.

Ingalhalikar, M., Smith, A., Parker, D., Satterthwaite, T., Elliott, M., Ruparel, K., et al. (2014). Sex differences in the structural connectome of the human brain. Proceedings of the National Academy of Sciences, 111(2), 823-828. 
Jia, W., Zhu, H., Ni, Y., Su, J., Xu, R., Jia, H., et al. (2020). Disruptions of frontoparietal control network and default mode network linking the metacognitive deficits with clinical symptoms in schizophrenia. Human Brain Mapping, 41(6), 1445-1458.

Joel, D. (2011). Male or female? Brains are intersex. Frontiers of Intergretive Neuroscience, 5, 1-9. doi: $103389 /$ fnint 201100057

Joel, D., \& Fausto-Sterling, A. (2016). Beyond sex differences: new approaches for thinking about variation in brain structure and function. Philosophical Transactions of the Royal Society B: Biological Sciences, 371(1688), 20150451.

Joel, D., \& McCarthy, M. (2017). Incorporating sex as a biological variable in neuropsychiatric research: where are we now and where should we be?. Neuropsychopharmacology, 42(2), 379.

Joel, D., Garcia-Falgueras, A., \& Swaab, D. (2020). The complex relationships between sex and the brain. The Neuroscientist, 26(2), 156-169.

Johanson, M., Vaurio, O., Tiihonen, J., \& Lähteenvuo, M. (2020). A systematic literature review of neuroimaging of psychopathic traits. Frontiers in psychiatry, 10, 1027.

Johnson, M., Dismukes, A., Vitacco, M., Breiman, C., Fleury, D., \& Shirtcliff, E. (2014). Psychopathy's influence on the coupling between hypothalamic-pituitary-adrenal andgonadal axes among incarcerated adolescents. Developmental Psychobiology, 56(3), 448458.

Jones, R., \& Lopez, K. (2014). Human reproductive biology. Chapter Sixteen. Academic Press.

Jones, R., Wheelwright, S., Farrell, K., Martin, E., Green, R., Di Ceglie, D., \& BaronCohen, S. (2012). Brief report: female-to-male transsexual people and autistic traits. Journal of Autism and Developmental Disorders, 42(2), 301-306.

Kaiser, A. (2012). Re-conceptualizing "sex" and "gender" in the human brain. Zeitschrift für Psychologie.

Kaczkurkin, A., Moore, T., Ruparel, K., Ciric, R., Calkins, M., Shinohara, R., ... \& Satterthwaite, T. (2016). Elevated amygdala perfusion mediates developmental sex differences in trait anxiety. Biological Psychiatry, 80(10), 775-785.

Killeen, P. (2019). The non-Darwinian evolution of behavers and behaviors. Behavioural processes, 161, 45-53.

Nergaard, K. (2019). Empathic expressions among three-year-olds in play and interaction in ECEC institutions in Norway: Bodily empathic expressions purposed for peers' well-being and confirming relationships. Early Child Development and Care, 189(9), 1444-1456.

Klein, D., Wan, Y., Kamyab, S., Okuda, H., \& Sokol, R. (1994). Effects of toxic levels of lead on gene regulation in the male axis: increase in messenger ribonucleic acids and intracellular stores of gonadotrophs within the central nervous system. Biology of reproduction, 50(4), 802-811. 
Knickmeyer, R., Baron-Cohen, S., Raggatt, P., \& Taylor, K. (2005). Foetal testosterone, social relationships, and restricted interests in children. Journal of child psychology and psychiatry, 46(2), 198-210.

Kolla, N., Boileau, I., Karas, K., Watts, J., Rusjan, P., Houle, S., \& Mizrahi, R. (2021). Lower amygdala fatty acid amide hydrolase in violent offenders with antisocial personality disorder: an $[11 \mathrm{C}]$ CURB positron emission tomography study. Translational psychiatry, 11(1), 1-11.

Kopsida, E., Stergiakouli, E., Lynn, P., Wilkinson, L., \& Davies, W. (2009). The role of the $\mathrm{Y}$ chromosome in brain function. Open neuroendocrinology journal (Online), 2, 20.

Kret, M., \& De Gelder, B. (2012). A review on sex differences in processing emotional signals. Neuropsychologia, 50(7), 1211-1221.

Kreukels, B., \& Guillamon, A. (2016). Neuroimaging studies in people with gender incongruence. International Review of Psychiatry, 28(1), 120-128.

Kushnick, G. (2019). The Cradle of Humankind: Evolutionary Approaches to Technology and Parenting.

Kruijver, F., Zhou, J., Pool, C., Hofman, M., Gooren, L., \& Swaab, D. (2000). Male-tofemale transsexuals have female neuron numbers in a limbic nucleus. The Journal of Clinical Endocrinology \& Metabolism, 85(5), 2034-2041.

Kuiri-Hänninen, T., Sankilampi, U., \& Dunkel, L. (2014). Activation of the hypothalamicpituitary-gonadal axis in infancy: minipuberty. Hormone research in paediatrics, 82(2), 7380.

Kung, K. Li, G., Golding, J., \& Hines, M. (2018). Preschool gender-typed play behavior at age 3.5 years predicts physical aggression at age 13 years. Archives of sexual behavior, 47(4), 905-914.

Kurtoğlu, S., \& Baştuğ, O. (2014). Mini puberty and its interpretation. Turkish Archives of Pediatrics/Türk Pediatri Arşivi, 49(3), 186.

Lamm C, Decety J, Singer T (2011) Meta-analytic evidence for common and distinct neural networks associated with directly experienced pain and empathy for pain. Neuroimage 54: 2492-2502.

Lee, P., Nordenström, A., Houk, C., Ahmed, S., Auchus, R., Baratz, A., ... \& Mazur, T. (2016). Global disorders of sex development update since 2006: perceptions, approach and care. Hormone research in paediatrics, 85(3), 158-180.

Legato, M. (2018). Untangling the Gordian Knot of Human Sexuality: What Is the Biologic Basis of Variations in Sexual Phenotype?. Gender and the Genome, 2(3), 62-67.

Leinbach, M., \& Fagot, B. (1986). Acquisition of gender labels: A test for toddlers. Sex Roles, 15(11-12), 655-666.

Lenschow, C., \& Lima, S. (2020). In the mood for sex: Neural circuits for reproduction. Current Opinion in Neurobiology, 60, 155-168. 
Levine, H., Jørgensen, N., Martino-Andrade, A., Mendiola, J., Weksler-Derri, D., Mindlis, I., ... \& Swan, S. H. (2017). Temporal trends in sperm count: a systematic review and metaregression analysis. Human reproduction update, 23(6), 646-659.

Li, Q., Xiao, M., Song, S., Huang, Y., Chen, X., Liu, Y., \& Chen, H. (2020). The personality dispositions and resting-state neural correlates associated with aggressive children. Social cognitive and affective neuroscience, 15(9), 1004-1016.

Ligthart, L., Bartels, M., Hoekstra, R., Hudziak, J., \& Boomsma, D. I. (2005). Genetic contributions to subtypes of aggression. Twin Research and Human Genetics, 8(5), 483-491.

Ling, S., Raine, A., Waller, R., Ruparel, K., Loughead, J., \& Gur, R. (2020). Divergent Amygdala Volume Asymmetries for Male and Female Youth With High Versus Low Callous-Unemotional Traits. Crime \& Delinquency, 66(10), 1419-1437.

LoBue, V., DeLoache, J. (2009). On the detection of emotional facial expressions: Are girls really better than boys?. Behavioral and Brain Sciences, 32(5), 397

Loomes, R., Hull, L., \& Mandy, W. (2017). What is the male-to-female ratio in autism spectrum disorder? A systematic review and meta-analysis. Journal of the American Academy of Child \& Adolescent Psychiatry, 56(6), 466-474.

Lonstein, J., Pereira, M., Marler, C., \& Morrell, J. (2014). Parental behavior. Knobil and Neill's Physiology of Reproduction, 4th edition Elsevier, New York, 2371-2438.

Lorber, J. (2000) 'Using Gender to Undo Gender: A Feminist Degendering Movement', Feminist Theory 1(1): 79-85.

López, M., Pol, H., Franke, B., \& Klein, M. (2020). Localizing genomic regions contributing to the extremes of externalizing behavior: ADHD, aggressive and antisocial behaviors. bioRxiv, 750091.

Lotze, M., Domin, M., Gerlach, F., Gaser, C., Lueders, E., Schmidt, C., et al. (2019). Novel findings from 2,838 adult brains on sex differences in gray matter brain volume. Scientific reports, $9(1), 1-7$.

Low, B. (2015). Why sex matters: A Darwinian look at human behaviour. Princeton University Press.

Lu, C. (2020). A computational approach to analyzing and detecting trans-exclusionary radical feminists (TERFs) on Twitter.

Luders, E., Sánchez, F., Gaser, C., Toga, A., Narr, K., Hamilton, L., et al. (2009). Regional gray matter variation in male-to-female transsexualism. Neuroimage, 46(4), 904-907.

Luine, V. (2014). Estradiol and cognitive function: past, present and future. Hormones and behavior, 66(4), 602-618.

Lutchmaya, S., Baron-Cohen, S., \& Raggatt, P. (2002). Foetal testosterone and eye contact in 12-month-old human infants. Infant Behavior and Development, 25(3), 327-335.

MacMaster, F., Keshavan, M., Mirza, Y., Carrey, N., Upadhyaya, A., El-Sheikh, R., et al. (2007). Development and sexual dimorphism of the pituitary gland. Life sciences, 80(10), 940-944. 
Maeda, Y., \& Yoon, S. (2013). A meta-analysis on gender differences in mental rotation ability measured by the Purdue spatial visualization tests: Visualization of rotations (PSVT: R). Educational Psychology Review, 25(1), 69-94.

Majid, D., Burke, S., Manzouri, A., Moody, T., Dhejne, C., Feusner, J., \& Savic, I. (2020). Neural systems for own-body processing align with gender identity rather than birthassigned sex. Cerebral Cortex, 30(5), 2897-2909.

Manzouri, A., Kosidou, K., \& Savic, I. (2017). Anatomical and functional findings in female-to-male transsexuals: testing a new hypothesis. Cerebral cortex, 27(2), 998-1010.

Marsh, R., Gerber, A., \& Peterson, B. (2008). Neuroimaging studies of normal brain development and their relevance for understanding childhood neuropsychiatric

disorders. Journal of the American Academy of Child \& Adolescent Psychiatry, 47(11), 1233-1251.

Marwha, D., Halari, M., \& Eliot, L. (2017). Meta-analysis reveals a lack of sexual dimorphism in human amygdala volume. Neuroimage, 147, 282-294.

McCarthy, M., \& Arnold, A. (2011). Reframing sexual differentiation of the brain. Nature neuroscience, 14(6), 677.

McCarthy, M., \& Konkle, A. (2005). When is a sex difference not a sex difference?. Frontiers in neuroendocrinology, 26(2), 85-102.

McCarthy, M., Arnold, A., Ball, G., Blaustein, J., \& De Vries, J. (2012). Sex differences in the brain: the not so inconvenient truth. Journal of Neuroscience, 32(7), 2241-2247

McCarthy, M., De Vries, G., \& Forger, N. (2017). Sexual differentiation of the brain: a fresh look at mode, mechanisms, and meaning. Hormones, Brain and Behavior (Third Edition), 5, 3-32. doi: 10.1016/B978-0-12-803592-4.00091-2

McCarthy, M., Pickett, L., VanRyzin, J., \& Kight, K. (2015). Surprising origins of sex differences in the brain. Hormones and behavior, 76, 3-10.

McClure, E., Monk, C., Nelson, E., Zarahn, E., Leibenluft, E., Bilder, R., et al. (2004). A developmental examination of gender differences in brain engagement during evaluation of threat. Biological psychiatry, 55(11), 1047-1055.

McEwen, B. (2001). Invited review: Estrogens effects on the brain: multiple sites and molecular mechanisms. Journal of applied physiology, 91(6), 2785-2801.

McFadden, J. (2021). Brain Wifi. Retrieved from https://aeon.co/essays/does-consciousnesscome-from-the-brains-electromagnetic-

field?utm source $=$ Aeon + Newsletter\&utm campaign $=3 \mathrm{f} 36 \mathrm{f} 37 \mathrm{e} 06-$

EMAIL_CAMPAIGN_2021 $0408 \quad 04$ 54\&utm_medium $=$ email\&utm term $=0$ 411a82e59 d-3f36f37e06-70920655. Visited April 10, 2021.

McFadden, D. (1998). Sex differences in the auditory system. Developmental Neuropsychology, 14(2-3), 261-298.

Meethal, S., \& Atwood, C. (2005). The role of hypothalamic-pituitary-gonadal hormones in the normal structure and functioning of the brain. Cell Mol Life Sci, 62(3), 257-270. 
Menger, Y., Bettscheider, M., Murgatroyd, C., \& Spengler, D. (2010). Sex differences in brain epigenetics. Epigenomics, 2(6), 807-821.

Meyer-Bahlburg, H. (2019). "Diagnosing” Gender? Categorizing Gender-Identity Variants in the Anthropocene. Archives of sexual behavior, 1-9.

Mink, J. W. (1996). The basal ganglia: focused selection and inhibition of competing motor programs. Progress in neurobiology, 50(4), 381-425.

Moser, J., Moran, T., Kneip, C., Schroder, H., \& Larson, M. (2016). Sex moderates the association between symptoms of anxiety, but not obsessive compulsive disorder, and errormonitoring brain activity: A meta-analytic review. Psychophysiology, 53(1), 21-29.

Mueller, S., Landré, L., Wierckx, K., \& T'Sjoen, G. (2017). A structural magnetic resonance imaging study in transgender persons on cross-sex hormone therapy. Neuroendocrinology, 105(2), 123-130.

Montanez, A. (2017) Beyond XX and XY: The Extraordinary Complexity of Sex Determination. Scientific American. https://www.scientificamerican.com/article/beyond-xxand-xy-the-extraordinary-complexity-of-sex-determination/ Visited $20 \mathrm{March}, 2021$

Muranishi, M., Inokawa, H., Yamada, H., Ueda, Y., Matsumoto, N., Nakagawa, M., \& Kimura, M. (2011). Inactivation of the putamen selectively impairs reward history-based action selection. Experimental brain research, 209(2), 235-246.

Mustanski, B., DuPree, M., Nievergelt, C., Bocklandt, S., Schork, N., \& Hamer, D. (2005). A genomewide scan of male sexual orientation. Human genetics, 116(4), 272-278

Nave, G., Jung, W., Karlsson Linnér, R., Kable, J., \& Koellinger, P. (2019). Are bigger brains smarter? Evidence from a large-scale preregistered study. Psychological science, 30(1), 43-54.

Negri-Cesi, P., Colciago, A., Celotti, F., \& Motta, M. (2004). Sexual differentiation of the brain: role of testosterone and its active metabolites. Journal of endocrinological investigation, 27, 120-127.

Newman, S. (1999). The medial extended amygdala in male reproductive behaviour: a node in the mammalian social behavior network. Annals of the New York Academy of Sciences, 877(1), 242-257.

Ngun, T., Ghahramani, N., Sánchez, F., Bocklandt, S., \& Vilain, E. (2011). The genetics of sex differences in brain and behavior. Frontiers in neuroendocrinology, 32(2), 227-246.

Nicholas, L. (2012). The Shape of Selves (and Socialities) to Come: Post-Gender and PostSex Theory and Practice

Numan, M., \& Insel, T. (2006). The neurobiology of parental behavior (Vol. 1). Springer Science \& Business Media.

Orobio de Castro, B., Merk, W., Koops, W., Veerman, J. W., \& Bosch, J. D. (2005). Emotions in social information processing and their relations with reactive and proactive aggression in referred aggressive boys. Journal of Clinical Child and Adolescent Psychology, 34(1), 105-116. 
O'Hanlan, K., Gordon, J., \& Sullivan, M. (2018). Biological origins of sexual orientation and gender identity: Impact on health. Gynecologic oncology, 149(1), 33-42.

Olson, K., \& Gülgöz, S. (2018). Early findings from the transyouth project: Gender development in transgender children. Child Development Perspectives, 12(2), 93-97.

OpenStax. (2016). Anatomy \& Physiology. OpenStax CNX. Feb 26, 2016, viewed 1 January 2020, https://opentextbc.ca/anatomyandphysiology/chapter/28-2-embryonic-development/

Owen-Blakemore, J., Berenbaum, S., \& Liben, L. (2009). Gender development. New York: Psychology Press.

Pallayova, M., Brandeburova, A., \& Tokarova, D. (2019). Update on Sexual Dimorphism in Brain Structure-Function Interrelationships: A Literature Review. Applied

Psychophysiology and Biofeedback, 44(4), 271-284.

Parker, G. (2021). How Soon Hath Time... A History of Two "Seminal"

Publications. Cells, 10(287), https://doi.org/10.3390/cells10020287.

Paulus, M., Wörle, M., \& Christner, N. (2020). The emergence of human altruism:

Preschool children develop a norm for empathy-based comforting. Journal of Cognition and Development, 21(1), 104-124.

Pavlova, M. (2017). Sex and gender affect the social brain: beyond simplicity. Journal of Neuroscience Research, 95(1-2), 235-250.

Pearson, R., Lightman, S., \& Evans, J. (2009). Emotional sensitivity for motherhood: late pregnancy is associated with enhanced accuracy to encode emotional faces. Hormones and Behavior, 56(5), 557-563.

Pejić, S., Todorović, A., Stojiljković, V., Pavlović, I., Gavrilović, L., Popović, N., et al. (2015). Antioxidant status and sex hormones in women with simple endometrial hyperplasia. Basic Principles and Clinical Significance of Oxidative Stress. Gowder SJT (ed.). InTech, Rijeka, 243-79.

Peper, J., Brouwer, R., van Leeuwen, M., Schnack, H., Boomsma, D., Kahn, R., et al. (2010). HPG-axis hormones during puberty: A study on the association with hypothalamic and pituitary volumes. Psychoneuroendocrinology, 35(1), 133-140.

Perrin, P., Heesacker, M., Tiegs, T., Swan, L., Lawrence, A., Smith, M., et al. (2011). Aligning Mars and Venus: The social construction and instability of gender differences in romantic relationships. Sex Roles, 64(9-10), 613-628.

Pfaff, D. (2011). Man and woman: An inside story. New York: Oxford.

von Polier, G., Greimel, E., Konrad, K., Großheinrich, N., Kohls, G., Vloet, T., ... \& Schulte-Rüther, M. (2020). Neural correlates of empathy in boys with early onset conduct disorder. Frontiers in psychiatry, 11, 178.

Purves, D. (1989). Body and brain: A trophic theory of neural connections. Harvard University Press.

Rametti, G., Carrillo, B., Gomez-Gil, E., Junque, C., Zubiarre-Elorza, L., Segovia, S., et al. (2011). The microstructure of white matter in male to female transsexuals before cross-sex hormonal treatment. A DTI study. Journal of Psychiatric Research 45, 949-954. 
Ratnu, V., Emami, M., \& Bredy, T. (2017). Genetic and epigenetic factors underlying sex differences in the regulation of gene expression in the brain. Journal of neuroscience research, 95(1-2), 301-310.

Raz, G., Jacob, Y., Gonen, T., Winetraub, Y., Flash, T., Soreq, E., \& Hendler, T. (2014). Cry for her or cry with her: context-dependent dissociation of two modes of cinematic empathy reflected in network cohesion dynamics. Social cognitive and affective neuroscience, 9(1), 30-38.

Reber, J., \& Tranel, D. (2017). Sex differences in the functional lateralization of emotion and decision making in the human brain. Journal of neuroscience research, 95(1-2), 270278.

Rice, W., Friberg, U., \& Gavrilets, S. (2012). Homosexuality as a consequence of epigenetically canalized sexual development. The Quarterly review of biology, 87(4), 343368.

Rippon, G. (2017). Culture not biology is behind many differences between the sexes. New Scientist. https://www. newscientist. com/article/2144424-culture-not-biology-is-behindmany-differences-between-the-sexes.

Rippon, G., Jordan-Young, R., Kaiser, A., \& Fine, C. (2014). Recommendations for sex/gender neuroimaging research: key principles and implications for research design, analysis, and interpretation. Frontiers in human neuroscience, 8, 650.

Ristori, J., Cocchetti, C., Romani, A., Mazzoli, F., Vignozzi, L., Maggi, M., et al. (2020). Brain Sex Differences Related to Gender Identity Development: Genes or Hormones?. International Journal of Molecular Sciences, 21(6), 2123.

Ritchie, S., Cox, S., Shen, X., Lombardo, M., Reus, L., Alloza, C., et al. (2018). Sex differences in the adult human brain: evidence from 5216 UK biobank participants. Cerebral Cortex, 28(8), 2959-2975.

Roca, C., Schmidt, P., Altemus, M., Deuster, P., Danaceau, M., Putnam, K., et al. (2003). Differential menstrual cycle regulation of hypothalamic-pituitary-adrenal axis in women with premenstrual syndrome and controls. The Journal of Clinical Endocrinology \& Metabolism, 88(7), 3057-3063.

Rogol, A. (2020). Human sex chromosome aneuploidies: The hypothalamic-pituitarygonadal axis. In American Journal of Medical Genetics Part C: Seminars in Medical Genetics. Hoboken, USA: John Wiley \& Sons, Inc.

Romero-Martínez, Á., González, M., Lila, M., Gracia, E., Martí-Bonmatí, L., AlberichBayarri, Á., ... \& Moya-Albiol, L. (2019). The brain resting-state functional connectivity underlying violence proneness: Is it a reliable marker for neurocriminology? A systematic review. Behavioral Sciences, 9(1), 11.

Rose, E. (2010). Epigenetics: Blurring the Line Between Nature and Nurture. CMC Senior Theses. Paper 33.

Roselli, C. (2018). Neurobiology of gender identity and sexual orientation. Journal of neuroendocrinology, 30(7), e12562. 
Rossi, A., Fernandes, V., \& Desplan, C. (2017). Timing temporal transitions during brain development. Current opinion in neurobiology, 42, 84-92.

Roxo, M., Franceschini, P., Zubaran, C., Kleber, F.., \& Sander, J. (2011). The limbic system conception and its historical evolution. The scientific world journal, 11, 2427-2440.

Ruiz-Cortes, Z. (2012) Gonadal Sex Steroids: Production, Action and Interactions in Mammals. In: Sergej Ostojic (Eds.), Steroids -From Physiology to Clinical Medicine. https://doi.org/10.5772/52994

Sakata, J., \& Crews, D. (2004). Developmental sculpting of social phenotype and plasticity. Neuroscience \& Biobehavioral Reviews, 28(2), 95-112.

Salk, R., Hyde, J., \& Abramson, L. (2017). Gender differences in depression in representative national samples: Meta-analyses of diagnoses and symptoms. Psychological bulletin, 143(8), 783.

Saltzman, W., \& Maestripieri, D. (2011). The neuroendocrinology of primate maternal behavior. Progress in Neuro-Psychopharmacology and Biological Psychiatry, 35(5), 1192 1204.

Salzman, C. (2019). Amygdala. Encyclopedia Britannica. https://www.britannica.com/science/amygdala. Visited January 23, 2021.

Samuels, C. (1986). Bases for the infant's developing self-awareness. Human Development, 29(1), 36-48.

Sánchez, F., \& Vilain, E. (2013). Transgender identities: Research and controversies. In C. J. Patterson \& A. R. D'Augelli (Eds.), Handbook of psychology and sexual orientation (p. 42-54). Oxford University Press.

Davidson, M. (2007). Seeking refuge under the umbrella: Inclusion, exclusion, and organizing within the category transgender. Sexuality Research \& Social Policy, 4(4), 60-80. Sanchis-Segura, C., Ibañez-Gual, M.., Adrián-Ventura, J., Aguirre, N., Gómez-Cruz, Á., Avila, C., \& Forn, C. (2019). Sex differences in gray matter volume: how many and how large are they really?. Biology of sex Differences, 10(1), 1-19.

Sato, T., Matsumoto, T., Kawano, H., Watanabe, T., Uematsu, Y., Sekine, K., et al. (2004). Brain masculinization requires androgen receptor function. Proceedings of the National Academy of Sciences, 101(6), 1673-1678.

Savic, I., \& Arver, S. (2011). Sex dimorphism of the brain in male-to-female transsexuals. Cerebral Cortex, 21(11), 2525-2533.

Savic, I., Garcia-Falgueras, A., \& Swaab. D. (2010). Sexual differentiation of the human brain in relation to gender identity and sexual orientation, Progress in Brain Research, 186,41-62.

Savin-Williams, R. (2016). Sexual orientation: Categories or continuum? Commentary on Bailey et al.(2016). Psychological Science in the Public Interest, 17(2), 37-44.

Schieman, S., \& Van Gundy, K. (2000). The personal and social links between age and selfreported empathy. Social Psychology Quarterly, Vol. 63, No. 2, 152-174. 
Schulte-Rüther, M., Markowitsch, H., Shah, N.., Fink, G., \& Piefke, M. (2008). Gender differences in brain networks supporting empathy. Neuroimage, 42(1), 393-403.

Serano, J. (2016). Whipping Girl: A Transsexual Woman on Sexism and the Scapegoating of Femininity. Berkley, Seal Press.

Shuster, B., Depireux, D., Mong, J., \& Hertzano, R. (2019). Sex differences in hearing: Probing the role of estrogen signaling. The Journal of the Acoustical Society of America, 145(6), 3656-3663.

Siegal, M., \& Bergman, A. (2002). Waddington's canalization revisited: developmental stability and evolution. Proceedings of the National Academy of Sciences, 99(16), 1052810532 .

Simerly, R. (2002). Wired for reproduction: organization and development of sexually dimorphic circuits in the mammalian forebrain. Annual review of neuroscience, 25(1), 507536

Simerly, R. (2010). Sexual Differentiation of the Central Nervous System. In G. Lemke, (Ed.). Developmental neurobiology. Academic Press.

Sindermann, C., Cooper, A., \& Montag, C. (2019). Empathy, Autistic Tendencies, and Systemizing Tendencies-Relationships Between Standard Self-Report Measures. Frontiers in psychiatry, 10, 307.

Singer, T., \& Klimecki, O. (2014). Empathy and compassion. Current Biology, 24(18), R875-R878.

Sippell, W., Dörr, H., Bidlingmaier, F., \& Knorr, D. (1980). Plasma levels of aldosterone, corticosterone, 11-deoxycorticosterone, progesterone, 17-hydroxyprogesterone, cortisol, and cortisone during infancy and childhood. Pediatric Research, 14(1), 39-46.

Sisk, C. (2016). Hormone-dependent adolescent organization of socio-sexual behaviors in mammals. Current opinion in neurobiology, 38, 63-68.

Smith, E., Junger, J., Derntl, B., \& Habel, U. (2015). The transsexual brain-A review of findings on the neural basis of transsexualism. Neuroscience \& Biobehavioral Reviews, 59, 251-266.

Smith, M., Deady, D., Moore, F., Jones, B., Cornwell, R., Stirrat, M., et al. (2012). Maternal tendencies in women are associated with estrogen levels and facial femininity. Hormones and Behavior, 61(1), 12-16.

Sokolowski, K., \& Corbin, J. (2012). Wired for behaviors: from development to function of innate limbic system circuitry. Frontiers in molecular neuroscience, 5, 55.

Stam, D., Huang, Y., \& Van den Stock, J. (2019). Non-overlapping and Inverse Associations Between the Sexes in Structural Brain-Trait Associations. Frontiers in psychology, 10, 904.

Steensma, T., Biemond, R., de Boer, F., \& Cohen-Kettenis, P. (2011). Desisting and persisting gender dysphoria after childhood: a qualitative follow-up study. Clinical child psychology and psychiatry, 16(4), 499-516. 
Stevens, J., \& Hamann, S. (2012). Sex differences in brain activation to emotional stimuli: a meta-analysis of neuroimaging studies. Neuropsychologia, 50(7), 1578-1593.

Stiles, J., \& Jernigan, T. (2010). The basics of brain development. Neuropsychology review, 20(4), 327-348.

Strauss, P., Cook, A., Winter, S., Watson, V., Wright Toussaint, D., Lin, A. (2017). Trans

Pathways: the mental health experiences and care pathways of trans young people.

Summary of results. Telethon Kids Institute, Perth, Australia.

Stuijfzand, S., De Wied, M., Kempes, M., Van de Graaff, J., Branje, S., \& Meeus, W. (2016). Gender differences in empathic sadness towards persons of the same-versus othersex during adolescence. Sex roles, 75(9), 434-446.

Sunstein, C. (2020). The triumph of the friendly: A review of Brian Hare and Vanessa Woods, survival of the friendliest. Journal of Bioeconomics, 1-5.

Swaab, D. (2004). Sexual differentiation of the human brain: relevance for gender identity, transsexualism and sexual orientation. Gynecological Endocrinology, 19(6), 301-312.

Swaab, D. (2007). Sexual differentiation of the brain and behavior. Best practice \& research clinical endocrinology \& metabolism, 21(3), 431-444.

Swaab, D., \& Garcia-Falgueras, (2009). Sexual differentiation of the human brain in relation to gender identity and sexual orientation. Functional Neurology, 24(1), 17.

Swain, J., Lorberbaum, J., Kose, S., \& Strathearn, L. (2007). Brain basis of early parentinfant interactions: psychology, physiology, and in vivo functional neuroimaging studies. Journal of child psychology and psychiatry, 48(3-4), 262-287.

Sweatt, J., Nestler, E., Meaney, M., \& Akbarian, S. (2013). An overview of the molecular basis of epigenetics. In: J. Sweatt, M. Meaney, \& E. Nestler (Eds.), Epigenetic regulation in the nervous system: Basic mechanisms and clinical impact. Academic Press. doi: 10 1016/B978-0-12-391494-1 00001-X

Tasopoulos, C. (2018). Human Sexual Differentiation and Aberration Spectrum. Encephalos, 55, 25-29.

Tay, P., Ting, Y., \& Tan, K. (2019). Sex and Care: The evolutionary psychological explanations for sex differences in formal care occupations. Frontiers in psychology, 10, 867.

Taylor, S., Klein, L., Lewis, B., Gruenewald, T., Gurung, R., \& Updegraff, J. (2000). Biobehavioral responses to stress in females: tend-and-befriend, not fight-or-flight. Psychological review, 107(3), 411.

Temple-Newhook, J., Pyne, J., Winters, K., Feder, S., Holmes, C., Tosh, J., et al. (2018). A critical commentary on follow-up studies and "desistance" theories about transgender and gender-nonconforming children. International Journal of Transgenderism, 19(2), pp.212224.

Theisen, J., Sundaram, V., Filchak, M., Chorich, L., Sullivan, M., Knight, J., et al. (2019). The use of whole exome sequencing in a cohort of transgender individuals to identify rare genetic variants. Scientific Reports, 9(1), 1-11. 
Thrower, E., Bretherton, I., Pang, K., Zajac, J., \& Cheung, A. (2020). Prevalence of autism spectrum disorder and attention-deficit hyperactivity disorder amongst individuals with gender dysphoria: a systematic review. Journal of autism and developmental disorders, 50(3), 695-706.

Toscano, J., Bauman, M., Mason, W., \& Amaral, D. (2009). Interest in infants by female rhesus monkeys with neonatal lesions of the amygdala or hippocampus. Neuroscience, 162(4), 881-891.

Tozzi, A., Durante, V., Manca, P., Di Mauro, M., Blasi, J., Grassi, S., et al. (2019). Bidirectional synaptic plasticity is driven by sex neurosteroids targeting estrogen and androgen receptors in hippocampal CA1 pyramidal neurons. Frontiers in Cellular Neuroscience, 13, 534.

Tunç, B., Solmaz, B., Parker, D., Satterthwaite, T., Elliott, M., Calkins, M., et al. (2016). Establishing a link between sex-related differences in the structural connectome and behavior. Philosophical Transactions of the Royal Society B: Biological Sciences, 371(1688), 20150111.

Thurer, S. (2005). The end of gender: A psychological autopsy. Routledge.

Tsukahara, S., \& Morishita, M. (2020). Sexually Dimorphic Formation of the Preoptic Area and the Bed Nucleus of the Stria Terminalis by Neuroestrogens. Frontiers in Neuroscience, 14, 797.

Unger, E., Burke Jr, K., Yang, C., Bender, K., Fuller, P., \& Shah, N. (2015). Medial amygdala aromatase neurons regulate aggression in both sexes. Cell reports, 10(4), 453-462. Unger, R. (1979). Toward a redefinition of sex and gender. American Psychologist, 34(11), 1085 .

Uribe, C., Junque, C., Gómez-Gil, E., Abos, A., Mueller, S., \& Guillamon, A. (2020). Brain network interactions in transgender individuals with gender incongruence. Neuroimage, 211, 116613.

van Anders, S. (2015). Beyond sexual orientation: Integrating gender/sex and diverse sexualities via sexual configurations theory. Archives of Sexual Behavior, 1-37.

Vance, S., Ehrensaft, D., \& Rosenthal, S. (2014). Psychological and medical care of gender nonconforming youth. Pediatrics, 134(6), 1184-1192.

Verma, R., Balhara, Y., \& Gupta, C. (2011). Gender differences in stress response: Role of developmental and biological determinants. Industrial psychiatry journal, 20(1), 4.

Vigil, J. (2009). A socio-relational framework of sex differences in the expression of emotion. Behavioral and Brain Sciences, 32(5), 375.

Vogt, G. (2017). Facilitation of environmental adaptation and evolution by epigenetic phenotype variation: insights from clonal, invasive, polyploid, and domesticated animals. Environmental Epigenetics, 3(1).

Von Bertalanffy, L. (1993). General system theory: Foundations, development, applications. New York. Georges Braziller, Inc.. 
Watson, J. (1972). Smiling, cooing, and "the game". Merrill-Palmer Quarterly of Behavior and Development, 18(4), 323-339.

Weigel, N., Vodolaga, V., Shapoval, G., Kartashova, E., \& Safronenko, A. (2020). Modern Androgyny as a Manifestation of a Universal Personality. Journal of Talent Development and Excellence, 12(3s), 234-241.

West, C., \& Zimmerman, D. (2009). Accounting for doing gender. Gender \& society, 23(1), $112-122$.

Wheelock, M., Hect, J.., Hernandez-Andrade, E., Hassan, S., Romero, R., Eggebrecht, A., \& Thomason, M. (2019). Sex differences in functional connectivity during fetal brain development. Developmental cognitive neuroscience, 36, 100632.

Whittle, S., Barendse, M., Pozzi, E., Vijayakumar, N., \& Simmons, J. (2020). Pubertal hormones predict sex-specific trajectories of pituitary gland volume during the transition from childhood to adolescence. NeuroImage, 204, 116256.

Whittle, S., Yücel, M., Yap, M., \& Allen, N. (2011). Sex differences in the neural correlates of emotion: evidence from neuroimaging. Biological psychology, 87(3), 319-333.

Wierman, M. (2007). Sex steroid effects at target tissues: mechanisms of action. Advances in physiology education, 31(1), 26-33.

Wizemann, T., \& Pardue, M. (2001). Exploring the biological contributions to human health: does sex matter? Committee on understanding the biology of sex and gender differences. Board on Health Sciences Policy, Institute of Medicine. Retrieved from http://www.nap.edu/catalog/10028.html. Visited August 21, 2020.

Wong, L., Wang, L., D’amour, J., Yumita, T., Chen, G., Yamaguchi, T., et al. (2016). Effective modulation of male aggression through lateral septum to medial hypothalamus projection. Current biology, 26(5), 593-604.

Woodbury-Smith, M., Paterson, A., Szatmari, P., \& Scherer, S. (2020). Genome-wide association study of emotional empathy in children. Scientific reports, 10(1), 1-8.

Wynn, R., Høiseth, M., \& Pettersen, G. (2012). Psychopathy in women: theoretical and clinical perspectives. International journal of women's health, 4, 257.

Yang, L., Comninos, A., \& Dhillo, W. (2018). Intrinsic links among sex, emotion, and reproduction. Cellular and molecular life sciences, 75(12), 2197-2210.

Yang, Y., Joshi, S., Jahanshad, N., Thompson, P., \& Baker, L. (2017). Neural correlates of proactive and reactive aggression in adolescent twins. Aggressive behavior, 43(3), 230-240.

Yao, S., Bergan, J., Lanjuin, A., \& Dulac, C. (2017). Oxytocin signaling in the medial amygdala is required for sex discrimination of social cues. Elife, 6, e31373.

Zaidi, Z. (2010). Gender differences in human brain: a review. The open anatomy journal, 2(1).

Zell, E., Krizan, Z., \& Teeter, S. (2015). Evaluating gender similarities and differences using metasynthesis. American Psychologist, 70(1), 10. 
Zhu, W., Zhou, X., \& Xia, L. X. (2019). Brain structures and functional connectivity associated with individual differences in trait proactive aggression. Scientific reports, $9(1)$, $1-12$.

Zietsch, B., Morley, K., Shekar, S., Verweij, K., Keller, M., Macgregor, S., et al (2008). Genetic factors predisposing to homosexuality may increase mating success in heterosexuals. Evolution and Human Behavior, 29(6), 424-433.

Zucker, K. (2018). The myth of persistence: Response to "A critical commentary on followup studies and 'desistance' theories about transgender and gender non-conforming children" by Temple-Newhook et al. (2018). International Journal of Transgenderism, 19(2), 231245.

Zucker, K., Bradley, S. J., \& Sanikhani, M. (1997). Sex differences in referral rates of children with gender identity disorder: Some hypotheses. Journal of Abnormal Child Psychology, 25(3), 217-227.

Zuloaga, D., Jordan, C., Breedlove, S., \& Squire, L. (2009). Sexual differentiation of the brain. Developmental neurobiology, 348. 